\title{
Trip6 Promotes Dendritic Morphogenesis through Dephosphorylated GRIP1-Dependent Myosin VI and F-Actin Organization
}

\author{
Kaosheng Lv (吕考升), ${ }^{1 *}$ Liang Chen (陈亮), ${ }^{1 *}$ Yuanjun Li (李圆君), ${ }^{1}$ Zenglong Li (李曾龙), ${ }^{1}$ Pengli Zheng (郑鹏里), ${ }^{1}$ \\ Yingying Liu (刘盈盈), ${ }^{1}$ Jianguo Chen (陈建国), ${ }^{1,2}$ and Junlin Teng (滕俊琳) ${ }^{1}$ \\ ${ }^{1}$ Key Laboratory of Cell Proliferation and Differentiation of the Ministry of Education and State Key Laboratory of Bio-Membrane and Membrane \\ Bio-Engineering, College of Life Sciences, and ${ }^{2}$ Center for Quantitative Biology, Peking University, Beijing 100871, China
}

Thyroid receptor-interacting protein 6 (Trip6), a multifunctional protein belonging to the zyxin family of LIM proteins, is involved in various physiological and pathological processes, including cell migration and tumorigenesis. However, the role of Trip6 in neurons remains unknown. Here, we show that Trip6 is expressed in mouse hippocampal neurons and promotes dendritic morphogenesis. Through interaction with the glutamate receptor-interacting protein 1 (GRIP1) and myosin VI, Trip6 is crucial for the total dendritic length and the number of primary dendrites in cultured hippocampal neurons. Trip6 depletion reduces F-actin content and impairs dendritic morphology, and this phenocopies GRIP1 or myosin VI knockdown. Furthermore, phosphorylation of GRIP1 ${ }^{956 \mathrm{~T}}$ by AKT1 inhibits the interaction between GRIP1 and myosin VI, but facilitates GRIP1 binding to 14-3-3 protein, which is required for regulating F-actin organization and dendritic morphogenesis. Thus, the Trip6-GRIP1-myosin VI interaction and its regulation on F-actin network play a significant role in dendritic morphogenesis.

Key words: Trip6; GRIP1; myosin VI; 14-3-3; dendritic morphogenesis; F-actin organization

\section{Introduction}

The regulation of actin dynamics is crucial for neuronal morphogenesis (Mattson, 1999; Lee et al., 2013). Many proteins, including RhoA (Da Silva et al., 2003) and $\beta$-arrestin-2 (Pontrello et al., 2012), have been reported to regulate actin dynamics that contribute to dendritic development. Thyroid receptor-interacting protein 6 (Trip6, also known as ZRP-1), is a member of the zyxin family of LIM proteins, whose most established function is also to regulate F-actin organization in mammalian cells (Lin and Lin, 2011). Previous studies showed that Trip6 depletion in HeLa cells impairs focal adhesion and stress fiber formation, as well as actin reorganization (Bai et al., 2007). Unlike typical actin-associated proteins, Trip6 does not appear to bind to or regulate F-actin filaments directly. Rather, it interacts with supervillin at focal adhesion sites to change its structure and diminish its function (Takizawa et al., 2006), while endoglin, a type-I membrane gly-

Received May 26, 2014; revised Dec. 7, 2014; accepted Dec. 10, 2014.

Author contributions: J.C., J.T., K.L., and L.C. designed research; K.L., L.C., J.T., Y. Li, Z.L., P.Z., and Y. Liu performed research; J.C., J.T., K.L., L.C., Y. Li, Z.Li, and Y. Liu. analyzed data; J.C., J.T., K.L., and L.C. wrote the paper.

This work was supported by the National Natural Science Foundation of China (31071177) and the Major State Basic Research Development Program of China (973 Program; 2014CB542206). We thank R.L. Huganir (Johns Hopkins University) for the rat GRIP1 CDNA, R.M. Shaw (University of California San Francisco) for Lifeact-mCherry, and I.C. Bruce (Zhejiang University) for reading the manuscript.

${ }^{*}$ K.L. and L.C. contributed equally to this work.

The authors declare no competing financial interests.

Correspondence should be addressed to either of the following: Junlin Teng at the above address. E-mail: junlinteng@pku.edu.cn; or Jianguo Chen at the above address. E-mail: chenjg@pku.edu.cn.

DOI:10.1523/JNEUROSCI.2125-14.2015

Copyright $\odot 2015$ the authors $\quad 0270-6474 / 15 / 352559-13 \$ 15.00 / 0$ coprotein, translocates Trip6 from focal adhesion sites to actin stress fibers (Sanz-Rodriguez et al., 2004). However, these studies are limited to non-neuronal cells. Given that LIM proteins, including cysteine-rich protein- 1 and espinas, are increasingly reported to participate in neuronal architecture (Ma et al., 2011; Matsubara et al., 2011), it is interesting to investigate the possible role of Trip6 in neuronal morphogenesis.

Glutamate receptor-interacting protein 1 (GRIP1), an adaptor protein, was first identified through its interaction with the GluA2/3 subunit of the AMPA-type glutamate receptors (Dong et al., 1997). It regulates the distribution of AMPA receptors in internal compartments through various PDZ domain-mediated interacting proteins, such as liprin- $\alpha /$ SYD2 (Wyszynski et al., 2002), the neuronal endosomal protein NEEP21 (Steiner et al., 2005), the microtubule-associated protein 1B (MAP1B; Davidkova and Carroll, 2007), and Sec8 (Mao et al., 2010). GRIP1 is easily detected in the soma, dendritic shafts, axons, and even growth cones of neurons (Wyszynski et al., 1999, 2002). Despite its wide distribution, GRIP1 has been described as a scaffolding protein that specifically steers the microtubule motor kinesin-1 (also known as KIF5) toward dendrites but not axons (Setou et al., 2002). GRIP1 also mediates the trafficking of EphB2 receptors to dendrites by kinesin-1 and controls dendritic morphogenesis (Hoogenraad et al., 2005).

Myosin VI is an actin-based multifunctional motor for the transport of vesicles and protein cargoes, and has been implicated in a wide variety of intracellular processes, such as endocytosis, the maintenance of Golgi morphology, protein 
secretion, and epithelial cell migration (Frank et al., 2004; Roberts et al., 2004; Sweeney and Houdusse, 2007). However, the role of myosin VI in dendritic morphogenesis is still largely obscure.

Here, we show that Trip6 is required for F-actin organization and dendritic morphology of hippocampal neurons. Moreover, Trip6 interacts with GRIP1 and myosin VI, either of which functions essentially in regulation of F-actin organization and dendritic morphology.

\section{Materials and Methods}

DNA constructs. Trip6, AKT1, and myosin $\mathrm{Va}$, myosin $\mathrm{Vb}$ and myosin $\mathrm{VI}$ cargo-binding domain (CBD) cDNAs were obtained by PCR cloning from the cDNA library of embryonic day (E) 17 mouse brains. Mouse GRIP1 and myosin VI cDNAs were obtained from Proteintech. The rat GRIP1 cDNA was a kind gift from Dr. Richard L Huganir (Dong et al., 1999a). These cDNAs, their deletion mutants, and their dominant negative mutants were subcloned into vectors for expression in bacteria or mammalian cells. Lifeact-mCherry (Addgene plasmid 40908) was used and Lifeact-GFP was constructed by subcloning from Lifeact-mCherry into pEGFP-N1 vector (Clontech Laboratories).

RNAi sequence. The RNAi sequences were as follows: Trip6, 5'AATTGTTGCTCTGGATCGAAG-3' (Bai et al., 2007); GRIP1, 5'GAGATGTGGTGTGCTACAGAT-3' (Life Technologies); myosin VI, 5'-GACATCAGGGAGAAGCTTC-3' (Jung et al., 2006; with corresponding base mutations from human mRNA to mouse mRNA); AKT1628, 5' -CGCGTGACCATGAACGAGTTT-3'; and AKT1-642, 5'-GAG TTTGAGTACCTGAAGCT-3' (Vasudevan et al., 2009). Apart from the GRIP1 RNAi sequence, which was subcloned into pcDNA6.2-GW/ EmGFP (Life Technologies), all of the RNAi sequences were cloned into pSuper or pSuper-RFP vectors (OligoEngine). For the Trip6 RNAiresistant mutant, we mutated four bases without any amino acid changes and subcloned it into the corresponding vector.

Antibodies. Mouse and rabbit anti-GRIP1 polyclonal antibodies were generated using GST-GRIP1 (amino acids 801-1112) as the antigen. Mouse and rabbit anti-GFP polyclonal antibodies were generated using $6 \mathrm{xHis}-\mathrm{GFP}$ as the antigen. The rabbit anti-GRIP1 ${ }^{956 \mathrm{~T}}$ phosphorylationspecific (pGRIP1) polyclonal antibody was prepared by Abmart. The following commercial antibodies were used: mouse monoclonal antibodies against Trip6 (BD Biosciences), GRIP1 (BD Biosciences), MAP2 (Sigma-Aldrich), Tau (Tau-1, Roche), GFP (MBL International), GAPDH (BioLink), Flag (Sigma-Aldrich), and $\alpha$-tubulin (Sigma-Aldrich); rabbit polyclonal antibodies against Trip6 (Abnova), myosin VI (SigmaAldrich), myosin Va (Cell Signaling Technology), and Tom20 (Santa Cruz Biotechnology); rabbit monoclonal antibodies against AKT1 (Cell Signaling Technology) and phospho-AKT1 (Thr308; Cell Signaling Technology). The following secondary antibodies were used for immunoblotting: alkaline phosphatase (AP)-conjugated goat anti-mouse/anti-rabbit IgG and horseradish peroxidase (HRP)-conjugated goat anti-mouse/antirabbit IgG (Jackson ImmunoResearch). The following secondary antibodies were used for immunostaining: Alexa Fluor 488/568-conjugated goat anti-mouse/anti-rabbit IgG (Life Technologies). Atto 488/565/ $647 \mathrm{~N}$-phalloidin was obtained from Sigma-Aldrich.

Cell culture, transfection, and drug treatment. HEK293T cells were cultured in DMEM $/ 10 \% \mathrm{FBS}$ at $37^{\circ} \mathrm{C}$ with $5 \% \mathrm{CO}_{2}$. Primary hippocampal neurons were cultured as described previously (Teng et al., 2001). In brief, hippocampi dissected from E16.5 mouse embryos of either sex were digested in $0.25 \%$ trypsin (Amresco) for $15 \mathrm{~min}$ followed by trituration with a pipette. Dissociated neurons were plated onto poly-Llysine-coated coverslips in DMEM/10\% FBS for $4-5 \mathrm{~h}$ and then transferred to Minimum Essential Medium (Life Technologies) supplemented with $1.1 \%$ pyruvate, $20 \%$ glucose, $2 \%$ B27 (Life Technologies), $1 \%$ Glutamax I (Life Technologies), and 2\% horse serum (Life Technologies) at $37^{\circ} \mathrm{C}$ with $5 \% \mathrm{CO}_{2}$. Cells were plated at a low density $\left(1.5 \times 10^{5}\right.$ cells per $35 \mathrm{~mm}$ dish) for immunofluorescence and a high density $(6.0 \times$ $10^{5}$ cells per $35 \mathrm{~mm}$ dish) for transfection.

HEK293T cells were transfected by the standard calcium phosphate method. For the cultured hippocampal neurons, a modified calcium phosphate method was used as described previously (Jiang and Chen, 2006). For dendrite observation, the hippocampal neurons were transfected at $7 \mathrm{~d}$ in vitro (DIV).

HEK293T cells or neurons were deprived of serum for $36 \mathrm{~h}$ and then either left untreated or treated with insulin ( $5 \mu \mathrm{g} / \mathrm{ml}$; Sigma-Aldrich) in the absence or presence of wortmannin (100 nM; Beyotime Institute of Biotechnology) for $30 \mathrm{~min}$ before harvest.

Immunofluorescence. Cultured hippocampal neurons were washed with PBS twice and fixed with 4\% PFA in PBS at room temperature for 15 min. After washing with PBS, the cells were permeabilized with $0.2 \%$ Triton X-100 in PBS for 10 min and then washed extensively. Nonspecific binding was blocked with 5\% bovine serum albumin in PBS for $30 \mathrm{~min}$ followed by incubation with primary antibodies at $37^{\circ} \mathrm{C}$ for $2 \mathrm{~h}$ or at $4^{\circ} \mathrm{C}$ overnight. Cells were washed with PBS extensively and incubated with Alexa Fluor 488/568-conjugated secondary antibodies at room temperature for $1 \mathrm{~h}$. Samples were observed under the Zeiss LSM 710 equipped with a $100 \times / 1.4$ numerical aperture oil or L20 $\times / 1.0$ water-immersion objective len.

Immunoprecipitation and mass spectrometry. For immunoprecipitation, transfected HEK293T cells were extracted with immunoprecipitation buffer (50 mm Tris-HCl, pH 7.5, $150 \mathrm{~mm} \mathrm{NaCl,} 2$ mм EDTA, $0.1 \%$ SDS, $1 \%$ Triton X-100, and protease inhibitors). For immunoprecipitation from mouse whole-brain homogenates, the homogenates were fractionated to obtain P2 and P3 fractions as described previously (Suh et al., 2010). Briefly, brains were homogenized with the sucrose buffer $(320 \mathrm{~mm}$ sucrose, 20 mм HEPES, pH 7.4, 5 mм EDTA, 2 mм DTT, and protease inhibitors) at $4^{\circ} \mathrm{C}$. The homogenate was centrifuged at $800 \times g$ for $10 \mathrm{~min}$ at $4^{\circ} \mathrm{C}$ to remove cell debris and nuclei (P1). The supernatant (S1) was centrifuged at $9,200 \times g$ for $15 \mathrm{~min}$ at $4^{\circ} \mathrm{C}$. The resultant pellet was suspended with the sucrose buffer and centrifuged at $10,000 \times g$ for 20 $\min (\mathrm{P} 2)$, and the supernatant was further centrifuged at $12,000 \times g$ for 30 min to obtain the supernatant (S2). Soluble protein fraction (S3) and microsome-enriched pellet (P3) were obtained from the centrifugation of the S2 fraction at $167,000 \times g$ for $2 \mathrm{~h}$ at $4^{\circ} \mathrm{C}$. $\mathrm{P} 2$ and $\mathrm{P} 3$ fractions were extracted with the immunoprecipitation buffer. The supernatant from lysates was incubated with appropriate amounts of antibodies for $\geq 4 \mathrm{~h}$, and this was followed by the addition of $30 \mu \mathrm{l}$ of protein A-Sepharose beads (GE Healthcare Life Sciences) for $\geq 2 \mathrm{~h}$. Pellets were washed extensively with immunoprecipitation buffer and then boiled in SDS-PAGE loading buffer.

Overexpressed GFP-LR2+PDZ7 (GRIP1 fragment) from HEK293T cells was purified by immunoprecipitation with anti-GFP rabbit polyclonal antibody, and separated by SDS-PAGE. The expected bands were excised and trypsinized. Phosphopeptides were captured and enriched with $\mathrm{TiO}_{2}$ Mag Sepharose (GE Healthcare Life Sciences) followed by LCQ Deca XP Plus Analyzer liquid chromatography/mass spectrometry (Thermo Finnigan) analysis.

GST pull-down assay and immunoblotting. For pull-down assays, purified prokaryotic GST-fused proteins were incubated with glutathione Sepharose $4 \mathrm{~B}$ beads (GE Healthcare Life Sciences) for $2 \mathrm{~h}$ followed by extensive washing with PBS. The beads were incubated with the supernatants from cell lysates or brain homogenates at $4^{\circ} \mathrm{C}$ for $\geq 4 \mathrm{~h}$. The precipitates were washed extensively with immunoprecipitation buffer and analyzed by immunoblotting.

For immunoblotting, the samples were separated by SDS-PAGE, and the gel was then transferred to a polyvinylidene fluoride membrane. The membrane was blocked with $5 \%$ nonfat milk followed by incubation with primary antibodies at $37^{\circ} \mathrm{C}$ for $1 \mathrm{~h}$ or at $4^{\circ} \mathrm{C}$ overnight. After extensive washing, the membrane was blocked again and incubated with AP-conjugated or HRP-conjugated secondary antibodies at room temperature for $1 \mathrm{~h}$.

Phosphatase treatment. HEK293T cells were transfected with GFPLR2+PDZ7. Thirty-six hours after transfection, the cells were washed with ice-cold PBS twice and lysed with immunoprecipitation buffer at $4^{\circ} \mathrm{C}$ for $1 \mathrm{~h}$. The lysates were centrifuged at $12,000 \times g$ for $10 \mathrm{~min}$ to obtain the supernatant. GFP-LR2 + PDZ7 was then immunoprecipitated with anti-GFP rabbit polyclonal antibody. The sample was divided into three aliquots. One aliquot was left untreated, and the other two were washed extensively with their respective buffers before treatment either 
A

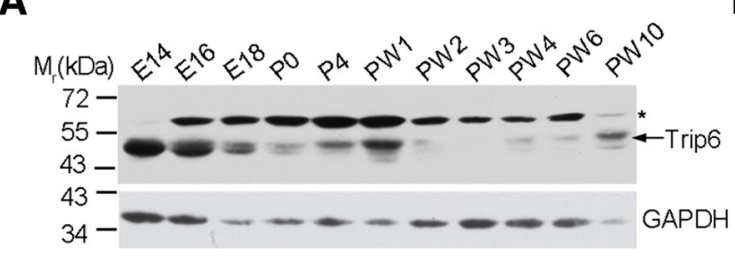

B

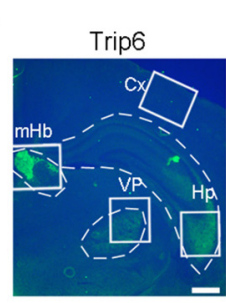

C

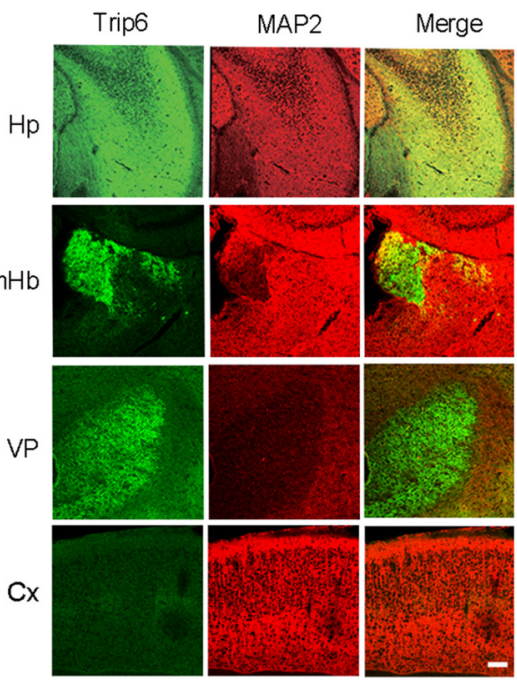

E
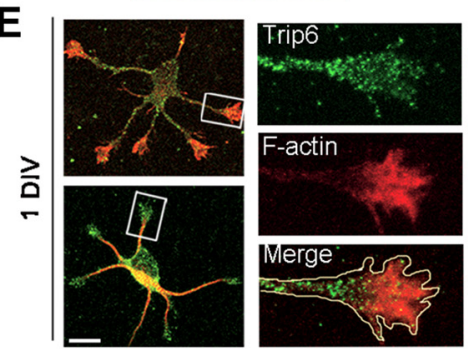

$\mathbf{F}$

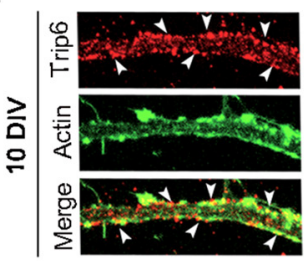

D

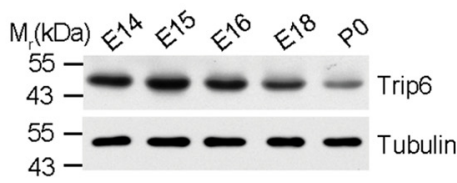

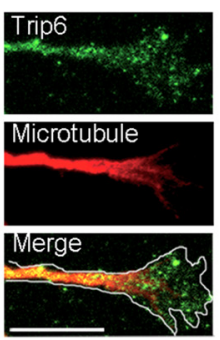

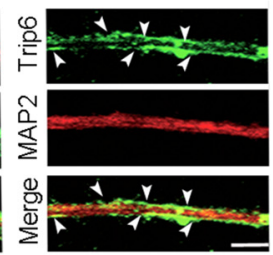

Figure 1. Localization of Trip6 in the mouse brain and cultured hippocampal neurons. $A$, Expression levels of Trip6 (arrow) in mouse whole-brain homogenates at different developmental stages. E, Embryonic day; P, Postnatal day; PW, Postnatal week. Asterisk indicates nonspecific bands. B, Immunostaining of Trip6 in PW1 mouse brain cryosection. Different regions are indicated by dashed lines. Note that Trip6 levels are expressed relatively higher in the hippocampus (Hp), medial habenular nucleus ( $\mathrm{mHb}$ ), and ventral posterior complex of the thalamus (VP). C $\mathrm{X}$, Cortex. Scale bar, 200 $\mu \mathrm{m}$. C, Magnified views of the boxed regions as indicated in B. Images of MAP2 immunostaining are also shown. Scale bar, $100 \mu \mathrm{m}$. D, Expression levels of Trip6 in mouse hippocampal homogenates at different developmental stages. $\boldsymbol{E}$, Immunostaining images of Trip6 in cultured hippocampal neurons at 1 day in vitro (DIV). The right panels show magnified views of the boxed regions in the left panels. The growth cones are outlined. F-actin was stained by phalloidin. Scale bars: left, $10 \mu \mathrm{m}$; right, $5 \mu \mathrm{m}$. $\boldsymbol{F}$, Immunostaining images of Trip6 in cultured hippocampal neurons at 10 DIV. Note that Trip6 was enriched in the periphery of dendrites (arrowheads) as indicated by phalloidin-stained F-actin. The dendrites were stained with anti-MAP2 antibody. Scale bar, $5 \mu \mathrm{m}$.

with $400 \mathrm{U}$ lambda phosphatase (Merck) at $30^{\circ} \mathrm{C}$ for 30 min or with 400 $\mathrm{U}$ of calf intestinal alkaline phosphatase (Promega) at $37^{\circ} \mathrm{C}$ for $30 \mathrm{~min}$. The samples were subjected to immunoblotting analysis.

Data analysis. For data analysis, cells or tissues were randomly allocated to treatment groups, images were picked randomly, and all experiments were double-blinded as previously described (Landis et al., 2012). The number of primary dendrites was counted manually. Total dendritic length and dendritic F-actin intensity were measured with ImageJ (National Institutes of Health). The Pearson's correlation coefficient for analyzing overlapped Trip6 and GRIP1 was calculated using ImageJ. Statistical analysis was conducted with GraphPad Prism 5 software with the unpaired two-tailed Student's $t$ test. The sample sizes were described in the figure legends.

\section{Results}

Trip6 is required for dendritic morphogenesis in hippocampal neurons

We first determined the expression level of Trip6 during mouse brain development. Immunoblotting analysis showed that Trip6 was highly expressed at E14 and E16, and then its expression decreased before birth (Fig. 1A). However, Trip6 increased after birth and reached a peak in the first postnatal week (PW1), while it exhibited relatively lower expression levels after this time (Fig. 1A). In PW1 mouse brain sections, Trip6 was highly expressed in the hippocampus, medial habenular nucleus, and ventral posterior complex of the thalamus, with negligible levels in the cortex (Fig. $1 B, C$ ). Similar to the whole brain (Fig. 1A), the hippocampus showed high Trip6 expression levels at E14-E16, and exhibited gradually decreased Trip6 before birth (Fig. 1D). Immunofluorescence staining showed that Trip6 was distributed throughout the soma, neurites, and growth cones (Fig. 1E) in 1 DIV neurons. In 10 DIV neurons, Trip6 was observed mainly in the periphery of dendrites, where actin is enriched (Fig. $1 F$ ).

Next, to assess the functional importance of Trip6 in neuronal morphogenesis, we overexpressed it in 7 DIV hippocampal neurons, and found that after $48 \mathrm{~h}$ compared with control, both the total dendritic length and the number of primary dendrites, marked with MAP2 immunostaining (Fig. $2 A$ ), were increased by 37.3 and $38.4 \%$, respectively (Fig. $2 B, C ; p<0.001$ ). Then, we used an shRNA (Bai et al., 2007) to deplete Trip6 (Fig. 2D,E), which reduced the total dendritic length by $35.1 \%$ and the number of primary dendrites by $43.5 \%$. This was reversed by coexpression of the Trip6 shRNA-resistant mutant (Figs. $2 F-H$; $p<$ $0.001)$. In contrast, we observed no significant change in the axonal length and branching following Trip6 knockdown (Fig. $2 I-K ; p>0.05)$. Together, these observations suggest that Trip6 is required for the dendritic morphology of hippocampal neurons.

\section{Trip6 interacts with GRIP1}

The LIM domains in the $\mathrm{C}$ terminus of Trip6 mediate its interaction with PDZ-domain proteins (Cuppen et al., 2000). GRIP1, a protein that contains seven PDZ domains, participates in dendritic morphogenesis (Hoogenraad et al., 2005). Thus, we hypothesized that the abundant Trip6 in dendrites might interact with GRIP1. To test this hypothesis, we first generated mouse and rabbit polyclonal antibodies against GRIP1 (Fig. 3A), and showed that GRIP1 was immunoprecipitated by the mouse anti-Trip6 
A

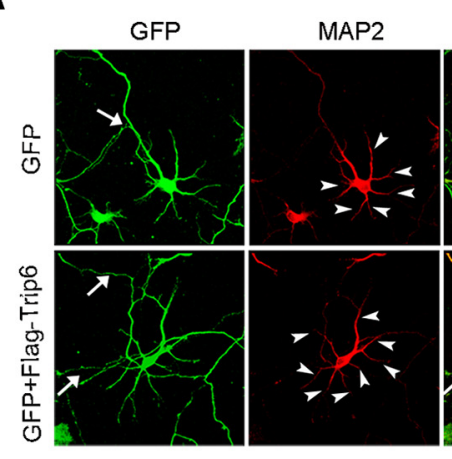

E

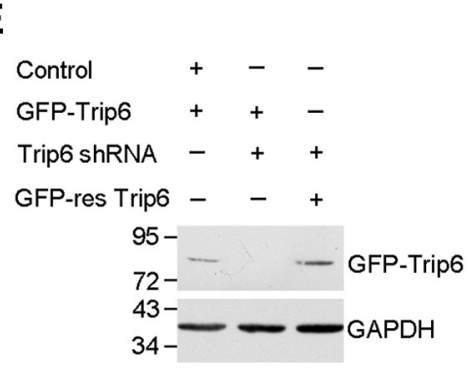

H

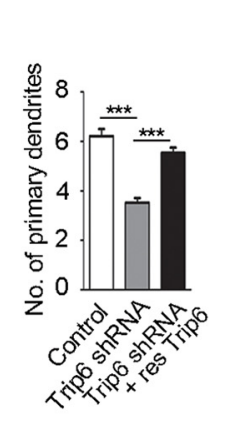

I

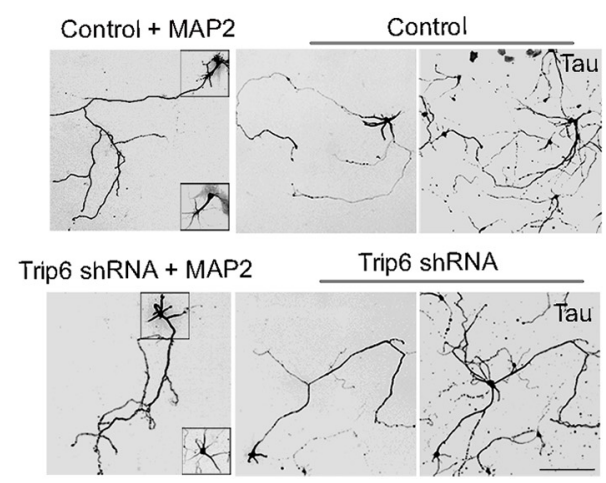

C

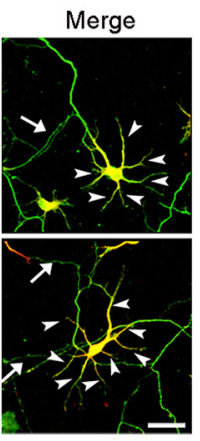

F

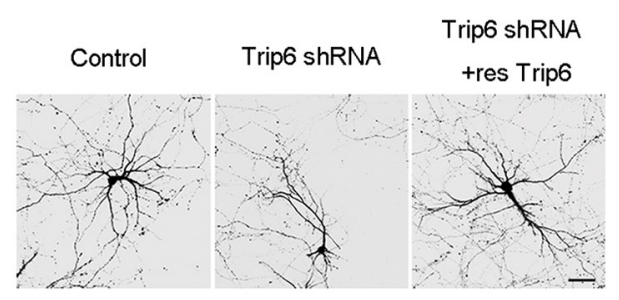

D

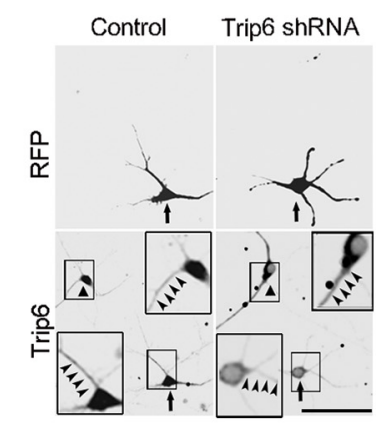

G

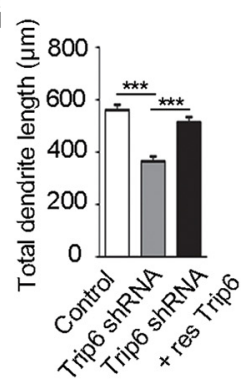

J

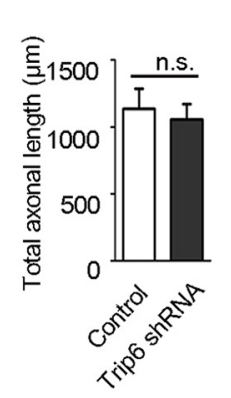

K

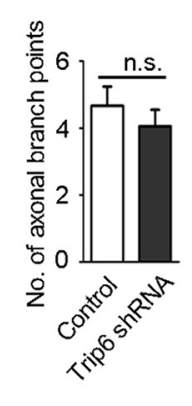

Figure 2. Trip6 promotes dendritic morphogenesis in cultured hippocampal neurons. $\boldsymbol{A}$, Representative images of cultured hippocampal neurons transfected with GFP or GFP together with Flag-Trip6 at 7 DIV for $48 \mathrm{~h}$. The morphology of the whole neuron was visualized by GFP fluorescence. Dendrites were identified by immunostaining with anti-MAP2 antibody (red, arrowheads). Axons are indicated with arrows. Scale bar, $20 \mu \mathrm{m}$. B, Quantification of the total dendritic length of neurons in $\boldsymbol{A}$ ( $n \geq 30$ cells). $\boldsymbol{C}$, Quantification of the number of primary dendrites of neurons in $\boldsymbol{A}$ ( $n \geq 30$ cells). D, Examination of the interference effect of Trip6 shRNA in cultured hippocampal neurons. The neurons were transfected with control shRNA or Trip6 shRNA at $2 \mathrm{DIV}$ for $72 \mathrm{~h}$ followed by staining with anti-Trip6 antibody. The RFP signal from the shRNA vector was used to visualize the transfected neurons (arrows). The untransfected neurons are indicated by triangles. Insets are the magnification of the boxed dendritic processes (arrowheads). Scale bar, $50 \mu \mathrm{m}$. $\boldsymbol{E}$, Examination of the interference effect of Trip6 shRNA in HEK293T cells. HEK293T cells were transfected with control shRNA or Trip6 shRNA together with GFP-Trip6 or GFP-tagged shRNA-resistant Trip6 mutant (GFP-res Trip6). Seventy-two hours after transfection, the cells were analyzed by immunoblotting. GAPDH was loaded as a negative control. $\boldsymbol{F}$, Representative images of neurons transfected with pSuper-RFP (control), Trip6 shRNA, or Trip6 shRNA together with its shRNA-resistant mutant (res Trip6) at 7 DIV for $72 \mathrm{~h}$. The RFP signal from the shRNA vector was used to visualize neuronal morphology. Scale bar, $50 \mu \mathrm{m}$. $\mathbf{G}$, Quantification of the total dendritic length of neurons in $\boldsymbol{F}$ ( $n \geq 30$ cells). $\boldsymbol{H}$, Quantification of the number of primary dendrites of neurons in $\boldsymbol{F}$ ( $n \geq 30$ cells). $\boldsymbol{I}$, Representative images of cultured hippocampal neurons transfected with control shRNA or Trip6 shRNA at 2 DIV for $72 \mathrm{~h}$. The RFP signal from the shRNA vector was used to visualize the transfected neurons. Insets show dendrites identified by immunostaining with anti-MAP 2 antibody. The tau-positive processes are also shown. Scale bar, $100 \mu \mathrm{m}$. $\boldsymbol{J}$, Quantification of the total axonal length of neurons in $\boldsymbol{I}(n \geq 30$ cells). $\boldsymbol{K}$, Quantification of the number of axonal branch points of neurons in $\boldsymbol{I}$ ( $n \geq$ 30 cells). For $\boldsymbol{B}, \boldsymbol{C}, \boldsymbol{G}, \boldsymbol{H}, \boldsymbol{J}$, and $\boldsymbol{K}$, data are mean \pm SEM. ${ }^{* * *} p<0.001$. n.s., No significance.

antibody in PW1 mouse brain homogenates (Fig. 3B). Next, we examined the localization of Trip6 and GRIP1 by coimmunostaining in cultured hippocampal neurons at $10 \mathrm{DIV}$, and calculated Pearson's coefficient of correlation between them. The results showed that they were partially colocalized in dendrites (Fig. 3C,D). Then, we generated a series of Trip6 or GRIP1 deletion mutants to identify the corresponding region of their interaction (Fig. $3 E, G$ ). Immunoprecipitation assays showed that the LIM3 domain of Trip6 and the PDZ123 domain of GRIP1 were indispensable for their interaction (Fig. $3 F, H$ ).

Next, to investigate the functional relationship between Trip6 and GRIP1 in dendritic morphogenesis, we first depleted GRIP1 with shRNAs (Fig. 4A,B). Similar to Trip6 knockdown, compared with control, GRIP1 depletion decreased the total dendrite length by $65.0 \%$ and the number of primary dendrites by $61.0 \%$ (Fig. $4 C-E ; p<0.001$ ), but showed no significant change in the axonal length and branching (Fig. $4 F-H ; p>0.05$ ), and this was consistent with the findings of a previous report (Hoogenraad et al., 2005). Furthermore, we evaluated the effects of Trip6 knockdown on GRIP1-depleted hippocampal neurons. The suppressive effects on dendritic morphogenesis showed no significant differences between Trip6 and GRIP1 doubleknockdown and Trip6 single-knockdown neurons (Fig. 4C-E; $p>0.05)$. The defects of GRIP1 knockdown on dendrites can 

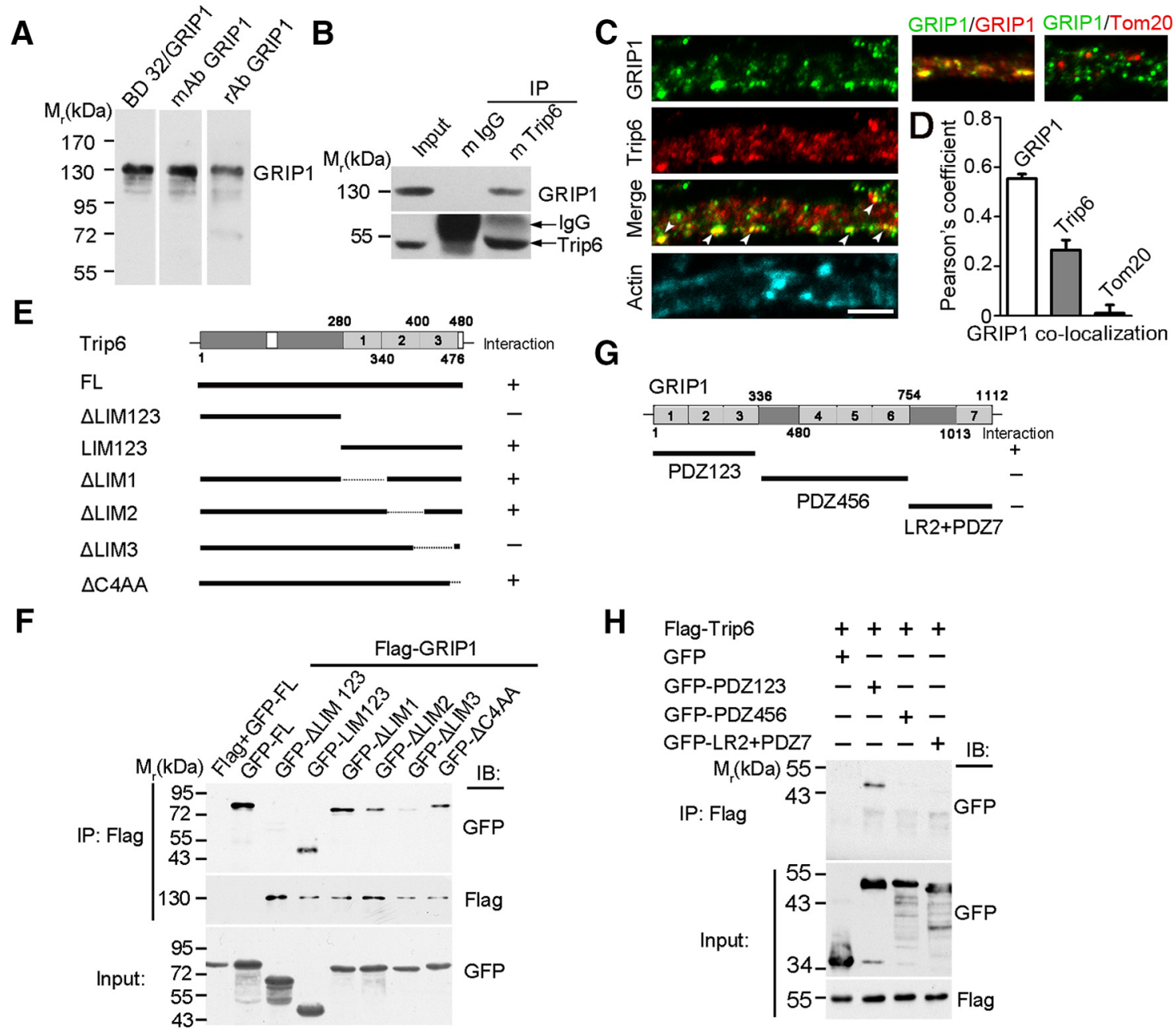

Figure 3. Trip6 LIM3 domain interacts with GRIP1 PDZ123-containing fragment. A, Mouse and rabbit anti-GRIP1 polyclonal antibodies were generated with GST-fused GRIP1-LR2 + PDZ7 as an antigen. Both antibodies were used to analyze the mouse brain homogenates by immunoblotting (IB), and they exhibited similar patterns of IB as the purchased antibody BD32/GRIP1. mAb, Mouse antibody; $r A b$, rabbit antibody. $\boldsymbol{B}$, Immunoprecipitation (IP) of GRIP1 from mouse brain homogenates with mouse anti-Trip6 antibody ( $\mathrm{m}$ Trip6). The input lane is $15 \%$ of input. $\boldsymbol{C}$, Immunostaining of GRIP1 (green) and Trip6 (red) in the dendrites of cultured hippocampal neurons at 10 DIV. Colocalization is marked with arrowheads. GRIP1 coimmunostaining with itself or mitochondrial marker Tom 20 was used as positive or negative control, respectively. Scale bar, $2 \mu \mathrm{m}$. D, Pearson's coefficient of GRIP1-Trip6 colocalization was analyzed ( $n \geq 10$ cells). Data are mean \pm SEM. E, Schematic of Trip6-deletion mutants. Dark gray, Proline-rich domain (PRD); light gray, LIM domain; $\triangle$ C4AA, deletion of four C-terminal amino acids; + , positive; - , negative. $\boldsymbol{F}$, IP assays were performed in HEK293T cells cotransfected with Flag-GRIP1 and the indicated GFP-tagged deletion mutants of Trip6. The immunoprecipitates were analyzed by IB. G, Schematic of GRIP1-deletion mutants. Dark gray, Linker region (LR); light gray, PDZ domain; +, positive; - , negative. H, IP assays were performed in HEK293T cells cotransfected with Flag-Trip6 and the indicated GFP-tagged deletion mutants of GRIP1, and the immunoprecipitates were analyzed by IB.

be rescued to a large extent by Trip6 overexpression (Fig. $4 I-K ; p<0.001)$. Together, these data indicate that Trip6 and GRIP1 function in the same signaling pathway to promote dendritic morphogenesis.

\section{Myosin VI involves in Trip6-GRIP1-mediated regulation of dendritic morphology and F-actin organization}

Considering that GRIP1 is an adaptor protein (Dong et al., 1999b) and interacts with kinesin-1 (Setou et al., 2002), we speculated that it might interact with other motors, like myosin VI or myosin V. To test this, we used the GST-fused CBDs of myosin $\mathrm{Va}, \mathrm{Vb}$, and $\mathrm{VI}$ to pull down mouse brain homogenates. GRIP1 was precipitated by GST-myosin VI-CBD, but not by GST alone or the GST-fused CBD of myosin Va or Vb (Fig. 5A). Immunoprecipitation assays of mouse brain homogenates confirmed the myosin VI-GRIP1 interaction (Fig. 5B). We then specified that the LR2 region of GRIP1 was responsible for myosin VI binding (Fig. 5C,D). Furthermore, the myosin VI-GRIP1-Trip6 complex was examined by GST-myosin VI-CBD pull-down assays with
HEK293T cells co-overexpressing GFP-Trip6 and Flag-GRIP1 (Fig. 5E).

To examine whether interrupting the function of myosin VI phenocopies Trip6 or GRIP1 knockdown with regard to dendritic morphogenesis, we overexpressed the myosin VI dominant negative mutant (Osterweil et al., 2005) in cultured hippocampal neurons and found that the neurons overexpressing the myosin-VI dominant negative mutant, but not the myosin Va or $\mathrm{Vb}$ dominant negative mutant, showed remarkable decreases in the total dendritic length by $70.6 \%$ and the number of primary dendrites by $79.3 \%$ (Fig. $5 F-H ; p<0.001$ ). A similar result was obtained with decreases of the total dendritic length by $70.2 \%$ and the number of primary dendrites by $68.6 \%$ when myosin VI was depleted by shRNA, and this effect on dendrites can be rescued by the shRNA-resistant myosin VI (Fig. $5 I-L ; p<0.001$ ). Moreover, double knockdown of Trip6 and myosin VI failed to exacerbate the defects of myosin VI knockdown neurons in dendritic morphology (Figs. $5 J-L ; p>0.05$ ), implying the involvement of myosin VI in Trip6-induced dendritic morphogenesis. 
A
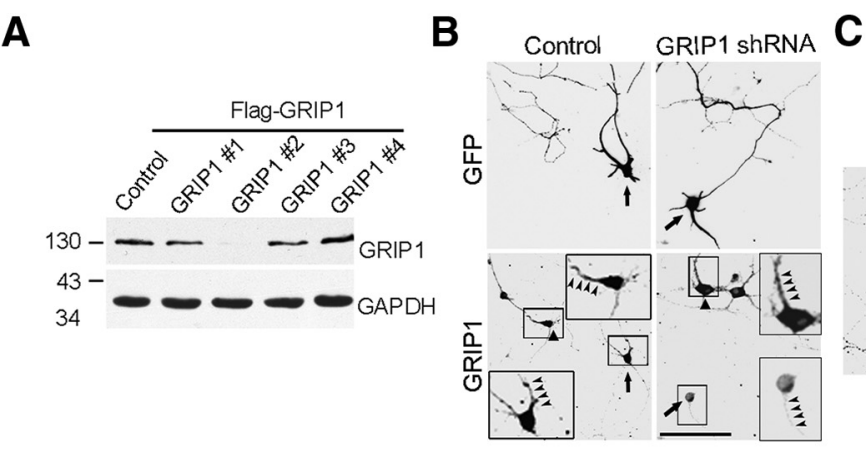

\section{C}
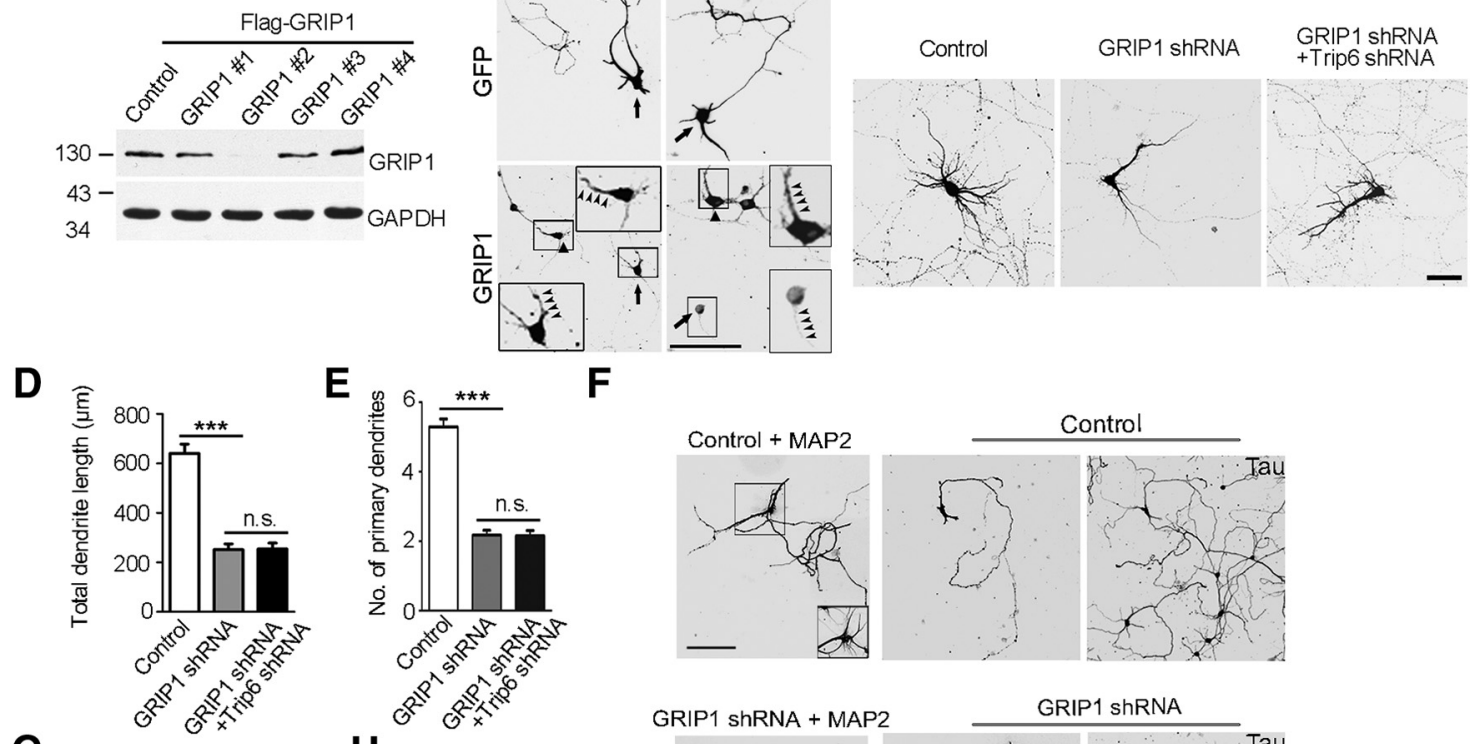

G

$\mathbf{E}_{\text {o. } 6, * * *} \mathbf{F}$

$\mathbf{F}$

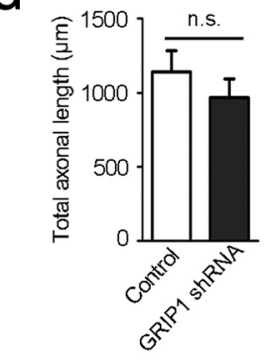

H
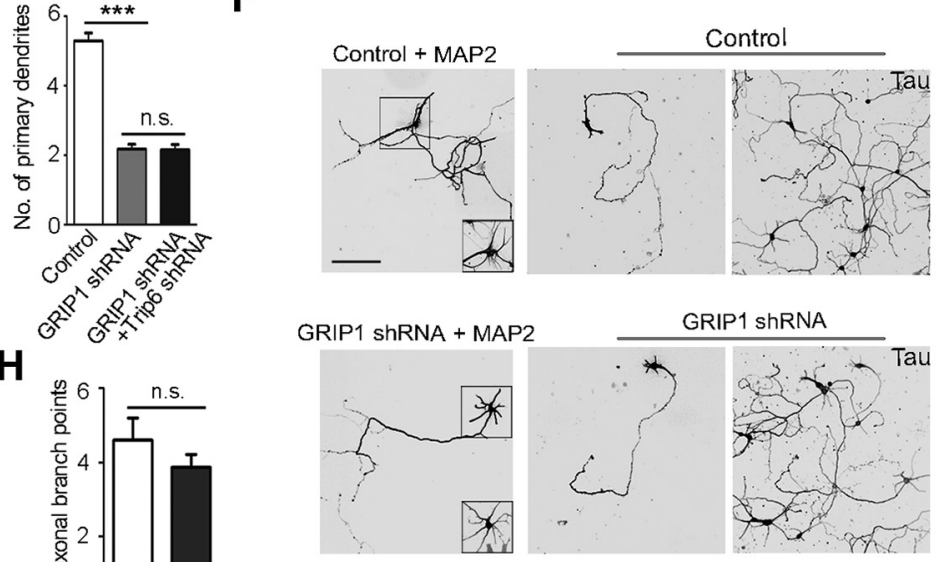

I
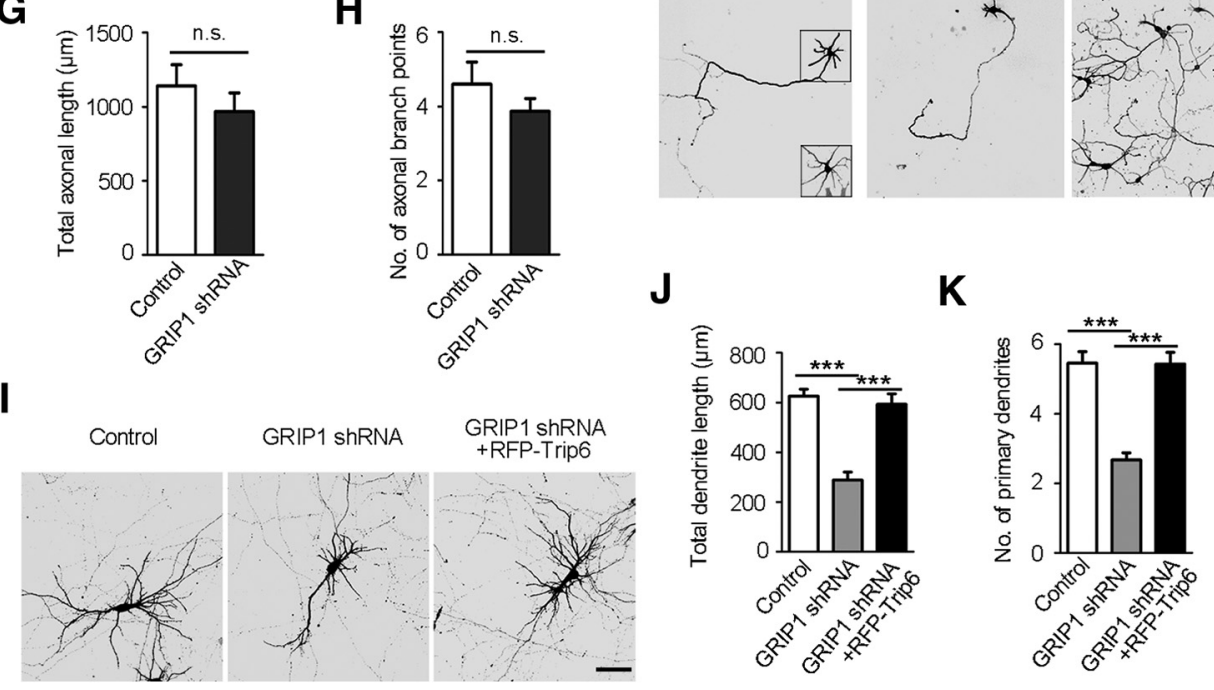

Figure 4. GRIP1 promotes dendritic morphogenesis through Trip6. $A$, Examination of the interference effect of GRIP1 shRNAs in HEK293T cells. Four pcDNA6.2-GW-based GRIP1 shRNA (GRIP1 shRNA 1\#, 2\#, 3\#, and 4\#) were cotransfected into HEK293T cells with Flag-GRIP1 for $72 \mathrm{~h}$ followed by immunoblotting analysis. B, Examination of the interference effect of GRIP1 shRNA in cultured hippocampal neurons. The neurons were transfected with control shRNA or GRIP1 shRNA at 2 DIV for $72 \mathrm{~h}$ followed by staining with anti-GRIP1 antibody. The GFP signal from the shRNA vector was used to visualize the transfected neurons (arrows). The untransfected neurons are indicated by triangles. Insets are the magnification of the boxed dendritic processes (arrowheads). Scale bar, 50 $\mu \mathrm{m}$. C, Representative images of cultured hippocampal neurons transfected with GRIP1 shRNA or GRIP1 and Trip6 double shRNA at 7 DIV for $72 \mathrm{~h}$. The GFP signal from the shRNA vector was used to visualize neuronal morphology. Scale bar, $50 \mu \mathrm{m}$. D, Quantification of the total dendritic length of neurons in $\boldsymbol{C}(n \geq 30$ cells). E, Quantification of the number of primary dendrites of neurons in $\boldsymbol{C}$ ( $n \geq 30$ cells). $\boldsymbol{F}$, Representative images of cultured hippocampal neurons transfected with control shRNA or GRIP1 shRNA at 2 DIV for $72 \mathrm{~h}$. The GFP signal from the shRNA vector was used to visualize the transfected neurons. Insets show dendrites identified by immunostaining with anti-MAP2 antibody. The tau-positive processes are also shown. Scale bar, $50 \mu \mathrm{m}$. G, $\boldsymbol{H}, \mathrm{Statistical}$ data of the total axonal length $(\boldsymbol{G})$ and the number of axonal branch points $(\boldsymbol{H})$ of neurons in $\boldsymbol{F}(n \geq 30$ cells). $\boldsymbol{I}$, Representative images of cultured hippocampal neurons transfected with GRIP1 shRNA or GRIP1 shRNA and RFP-Trip6 at 7 DIV for $72 \mathrm{~h}$. The GFP signal from the GRIP1 shRNA vector was used to visualize neuronal morphology. Scale bar, $50 \mu \mathrm{m}$. $J, \boldsymbol{K}$, Quantification of the total dendritic length $(\boldsymbol{J})$ and the number of primary dendrites $(\boldsymbol{K})$ of neurons in $\boldsymbol{I}\left(n \geq 30\right.$ cells). For $\boldsymbol{D}, \boldsymbol{E}, \boldsymbol{G}, \boldsymbol{H}, \boldsymbol{J}$, and $\boldsymbol{K}$, data are mean \pm SEM. ${ }^{* * *} p<0.001$; n.s., No significance.

In addition, knockdown of myosin VI also showed significant decreases in the axonal length and branching by $50.3 \%$ and $52.9 \%$, respectively (Fig. $5 M-O$; $p<0.001$ ), suggesting multifunctional roles of myosin VI in neuronal morphogenesis.

As Trip6 is shown to be involved in F-actin organization in non-neuronal cells (Bai et al., 2007; Lin and Lin, 2011), we set out to determine whether Trip6 affects actin organization in neurons. We used GFP-tagged Lifeact, a short amino acid peptide, to visualize F-actin of the cells (Riedl et al., 2008; Smyth et al., 2012), and found that compared with control, Trip6 knockdown in cultured hippocampal neurons resulted in a decrease of F-actin intensity by $41.1 \%$ with disrupted dendritic morphology (Fig. $5 P, Q ; p<$ 0.01 ). Similar phenotypes were also observed after knockdown of myosin VI or double knockdown of Trip6 and myosin VI, decreasing by $69.9 \%$ and $70.8 \%$, respectively (Fig. $5 P, Q ; p<0.001$ ), indicating that Trip6 and myosin VI function in the same signaling pathway to promote F-actin organization and dendritic growth.

\section{AKT1 phosphorylates GRIP1 ${ }^{956 \mathrm{~T}}$}

To investigate whether the GRIP1-myosin VI interaction is regulated by phosphorylation, a GFP-tagged fragment LR2 + PDZ7 of 
A

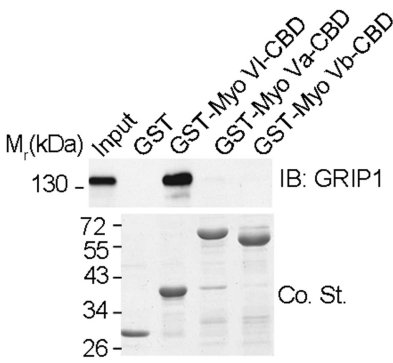

B

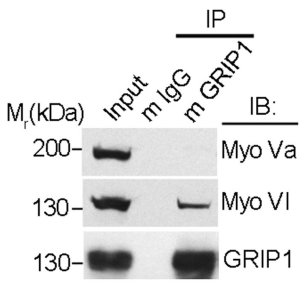

E

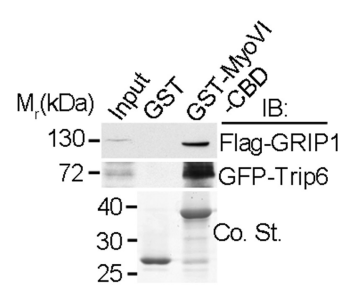

J

$\mathbf{F}$

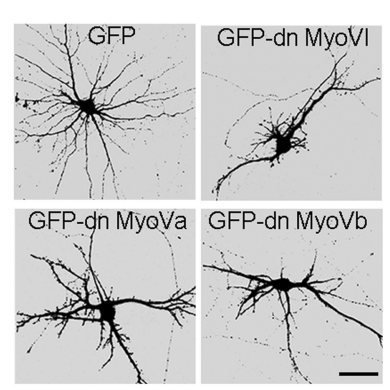

C

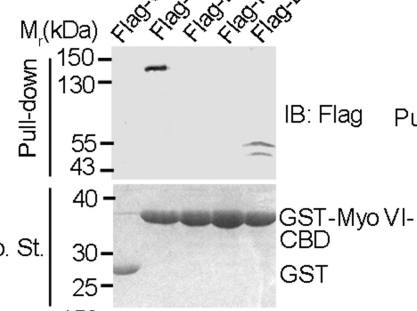

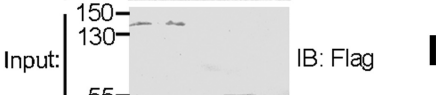

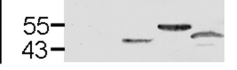

G

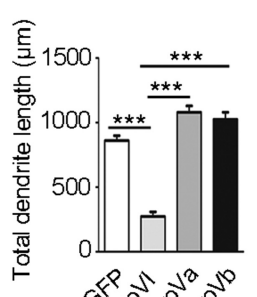

H

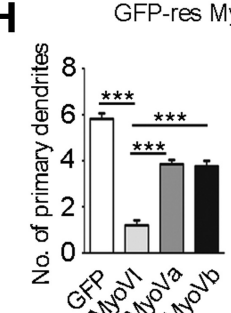

D

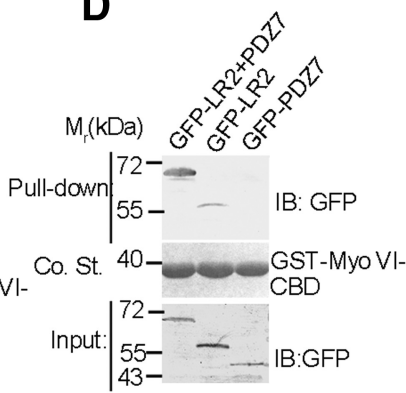

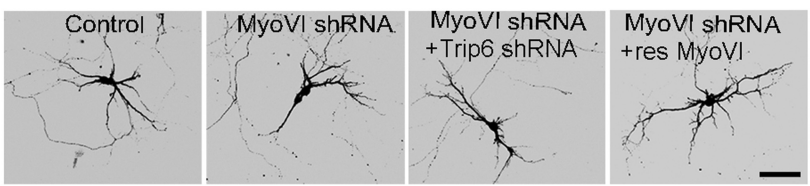

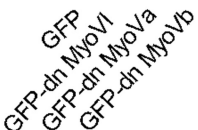

0

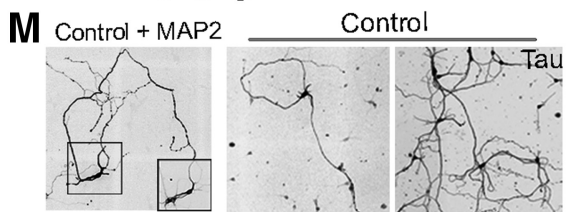

K

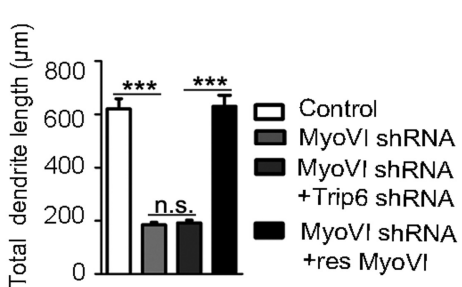

$\mathbf{L}$
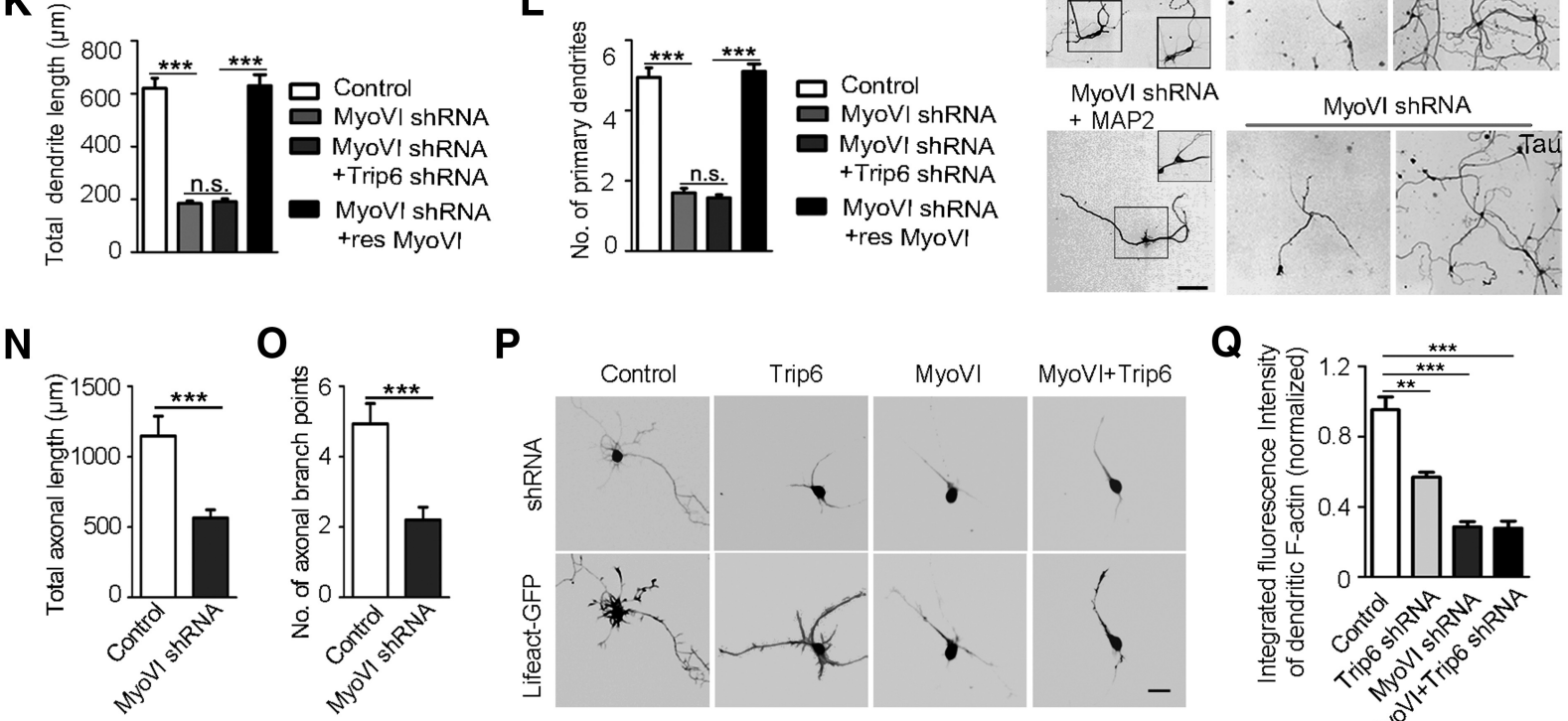

Q

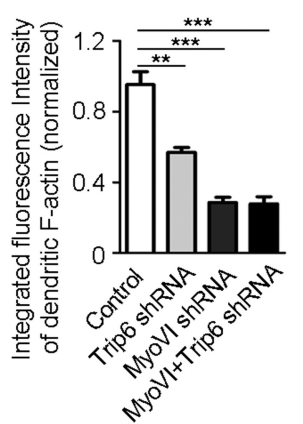

Figure 5. Myosin Vl interacts with GRIP1 and participates in Trip6-induced dendritic development and F-actin organization. $A$, GST, GST-myosin Va, GST-myosin Vb, and GST-myosin VI CBD were used to pull down mouse brain homogenates. The precipitates were analyzed by immunoblotting (IB) with anti-GRIP1 antibody. The input lane is $15 \%$ of input. Co. St., Coomassie blue staining. B, Immunoprecipitation (IP) of myosin VIfrom mouse brain homogenates with the mouse monoclonal antibody against GRIP1. The input lane is $15 \%$ of input. $C, D$, Cell lysates from HEK293T cells overexpressing the indicated GRIP1-deletion mutants were pulled down by GST or GST-myosin VI-CBD and analyzed by IB. E, Pull-down of overexpressed GFP-Trip6 and Flag-GRIP1 by GST-myosin VI-CBD in HEK293T cell lysates. $F$, Representative images of cultured hippocampal neurons transfected with GFP, GFP-tagged dominant negative (GFP-dn) myosin Va, Vb, or Vl at 7 DIV for 48 h. The GFP signal was used to visualize neuronal morphology. Scale bar, 20 $\mu \mathrm{m}$. G, Quantification of the total dendritic length of neurons in $\boldsymbol{F}(n \geq 30$ cells). $\boldsymbol{H}$, Quantification of the number of primary dendrites of neurons in $\boldsymbol{F}(n \geq 30$ cells). I, Examination of the interference effect of myosin VI shRNA in HEK293T cells. HEK293T cells were transfected with control shRNA or myosin VI shRNA together with GFP-myosin Vl or GFP-tagged shRNA-resistant myosin VI mutant (GFP-res myosin VI) for $72 \mathrm{~h}$ followed by IB. J, Representative images of cultured hippocampal neurons transfected with myosin VI shRNA, myosin VI and Trip6 double shRNA, or myosin VI shRNA and rescue-myosin VI (res Myo VI) at $7 \mathrm{DIV}$ for $72 \mathrm{~h}$. The RFP signal from the shRNA vector was used to visualize neuronal morphology. Scale bar, $50 \mu \mathrm{m}$. $K$, Quantification of the total dendritic length of the neurons in $J(n \geq 30$ cells). $L$, Quantification of the number of primary dendrites of neurons in $J(n \geq 30$ cells). $M$, Representative images of cultured hippocampal neurons transfected with control shRNA or myosin VI shRNA at 2 DIV for $72 \mathrm{~h}$. The RFP signal from the shRNA vector was used to visualize the transfected neurons. Insets show dendrites identified by immunostaining with anti-MAP2 antibody. The tau-positive processes are also shown. Scale bar, $50 \mu \mathrm{m}$. $\boldsymbol{N}, \boldsymbol{0}$, Statistical data of the total axonal length $(\boldsymbol{N})$ and the number of axonal branch points $(\boldsymbol{O})$ of neurons in $\boldsymbol{M}$ ( $n \geq 30$ cells). $\boldsymbol{P}$, Representative images of the cultured hippocampal neurons transfected with Lifeact-GFP together with control, with Trip6, with myosin VI, or with myosin VI and Trip6 double shRNA at 5 DIV for $48 \mathrm{~h}$. Scale bar, $10 \mu \mathrm{m}$. Q, Quantification of the integrated fluorescence intensity of dendritic F-actin in $\boldsymbol{P}\left(n \geq 30\right.$ cells). For $\mathbf{G}, \boldsymbol{H}, \boldsymbol{K}, \boldsymbol{L}, \boldsymbol{N}, \mathbf{O}$, and $\mathbf{Q}$, data are mean \pm SEM. ${ }^{* *} p<0.01 ;{ }^{* * *} p<0.001$. n.s., No significance. 
A

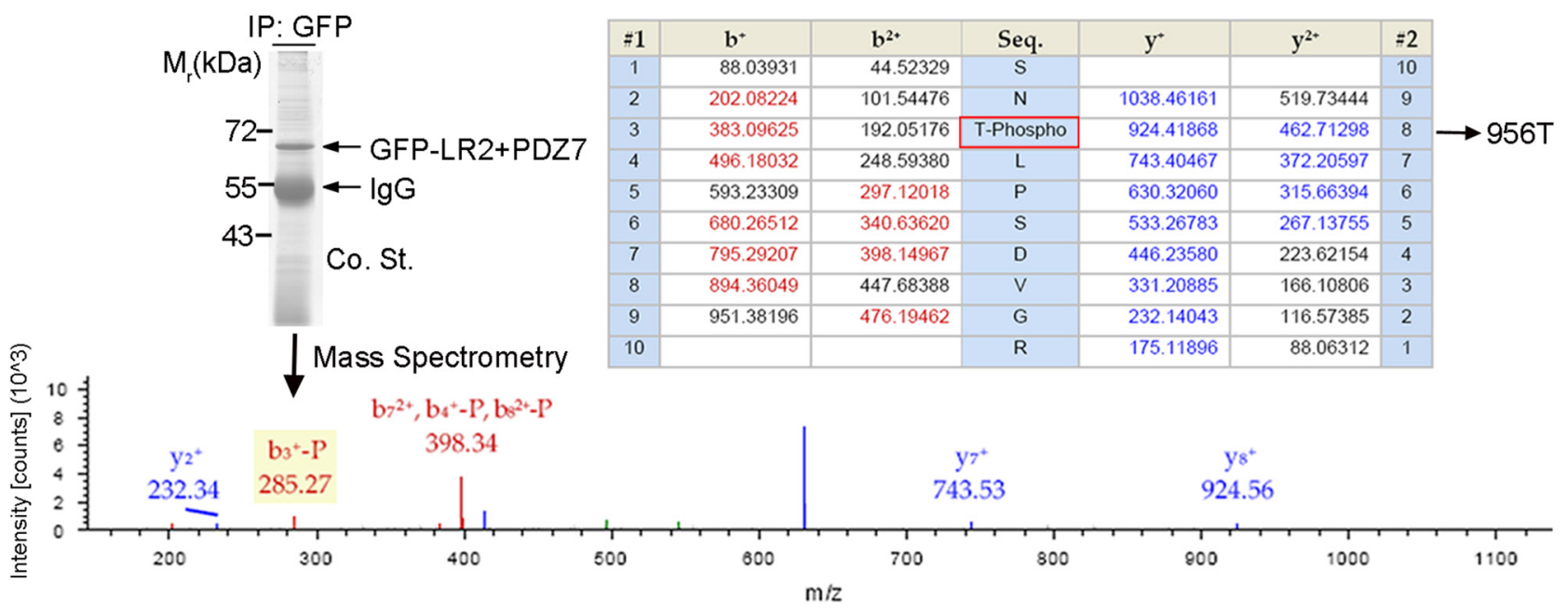

B

$\begin{array}{ccr} & 855 & 956 \\ \text { Homo sapiens } & \text { RSQTYPDVG }\end{array}$

Rattus norvegicus RSQTYPDVG...RSNTLP

Mus musculus RSQTYPDVG...RSNTLP

Pan troglodytes RSQTYPDVG...RSNTLP

Macaca mulatta RSQTYPDVG...RSNTLP

Xenopus tropicalis RNNHFHDTG...RSNTLP

Danio rerio RNN I LPDFG... RSNTLP

Predicted AKT1 motif

D

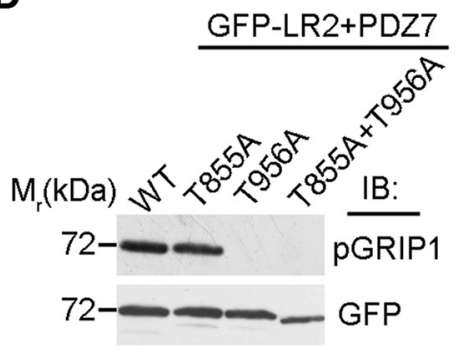

E
C

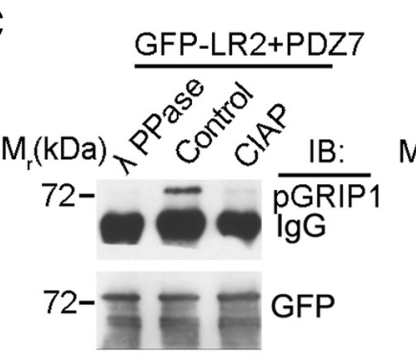

I

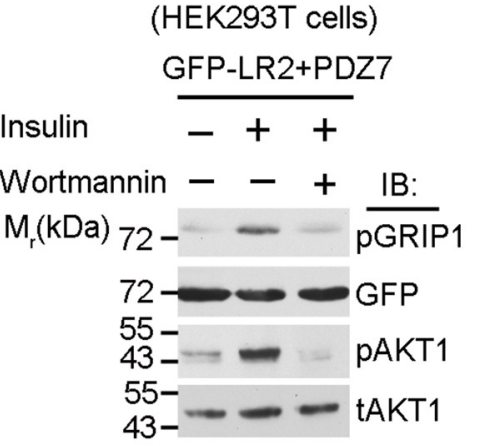

$\mathbf{F}$

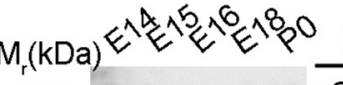

G

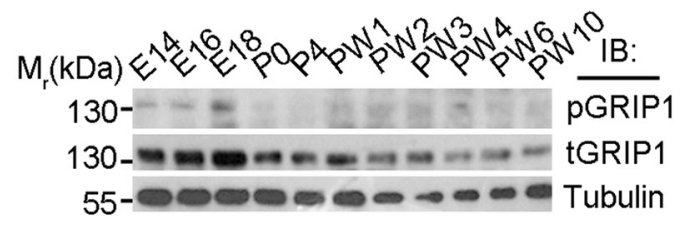

GFP-LR2+PDZ7 $0^{8} 6^{x^{2}}$

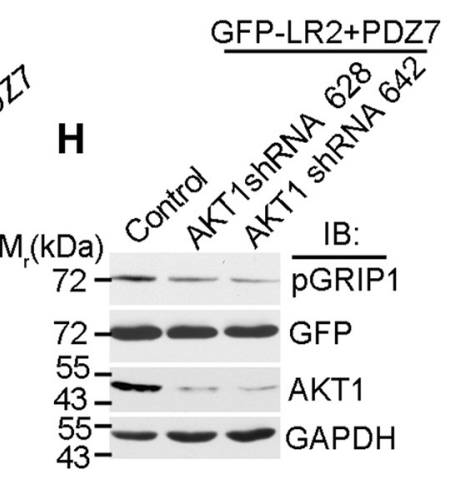

J Insulin $\frac{\text { WT }}{-} \frac{\text { T956A }}{-++}$ Wortmannin $---+\mathrm{IB}$ $\mathrm{M}_{\mathrm{r}}(\mathrm{kDa})$

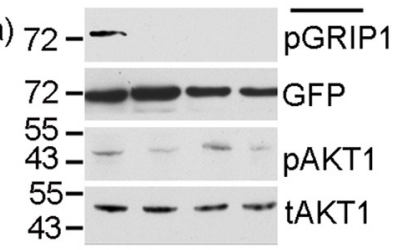

K

(Hippocampal neurons) Endogenous GRIP1 Insulin $-++$ Wortmannin - -+ IB: $\mathrm{M}_{\mathrm{r}}(\mathrm{kDa})$

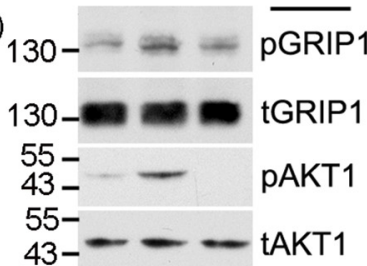

Figure 6. GRIP1 ${ }^{9561}$ is phosphorylated by AKT1. A, GFP-LR2 + PDZ7 (GRIP1 fragment) was immunoprecipitated (IP) with anti-GFP antibody and separated by SDS-PAGE followed by mass spectrometry analysis. Threonine at the 956 position (956T) was identified to be phosphorylated (red box). Co. St., Coomassie blue staining. B, Alignment of the amino acid sequence containing GRIP1 ${ }^{855 T}$ (negative control) and GRIP1 ${ }^{956 \mathrm{~T}}$ among different eukaryotes; $956 \mathrm{~T}$ is emphasized in bold and marked by an asterisk; the predicted AKT1-phosphorylated motif is indicated by the arrow. C, Overexpressed GFP-LR2 + PDZ7 (GRIP1 fragment) was immunoprecipitated from HEK293T cells with anti-GFP antibody and treated with lambda phosphatase ( $\lambda$ PPase) or calf intestine alkaline phosphatase (CIAP) followed by immunoblotting (IB) with anti-GRIP1 ${ }^{956 T}$ phosphorylation-specific antibody (pGRIP1). D, WT and phosphodead mutants T855A, T956A, and both T855A and T956A (T855A + T956A) of GFP-LR2 + PDZ7 were transfected into HEK293T cells and analyzed by IB with pGRIP1 antibody. E, $\boldsymbol{F}$, IB of phospho-GRIP1 ${ }^{9561}$ (pGRIP1) and total GRIP1 (tGRIP1) in the whole-brain $(\boldsymbol{E})$ and hippocampus $(\boldsymbol{F})$ homogenates of mice at different developmental stages. E, Embryonic day; P, Postnatal day; PW, Postnatal week. G, Pull-down of overexpressed GFP-AKT1 by GST-LR2 + PDZ7 in HEK293T cell lysates. H, GFP-LR2 + PDZ, together with AKT1 shRNA vector (628 or 642), was transfected into HEK293T cells for $72 \mathrm{~h}$ followed by IB. I, J, HEK293T cells overexpressing WT $(I)$ or T956A $(J)$ of GFP-LR2 + PDZ7 were treated with insulin alone or together with wortmannin following serum starvation for $36 \mathrm{~h}$ and then analyzed by IB with pGRIP1 antibody. $K$, Cultured hippocampal neurons were treated with insulin alone or together with wortmannin following serum starvation at 7 DIV for $36 \mathrm{~h}$ and then analyzed by IB with pGRIP1 antibody. 
A

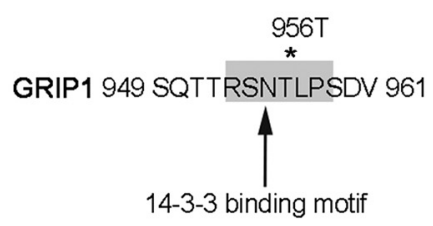

B

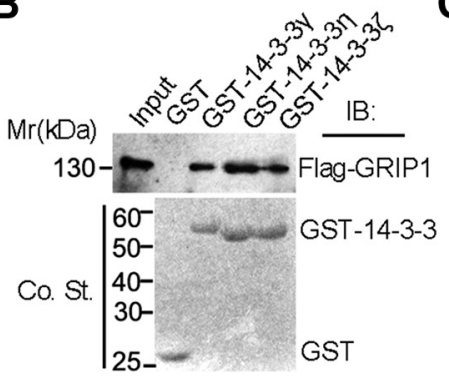

C

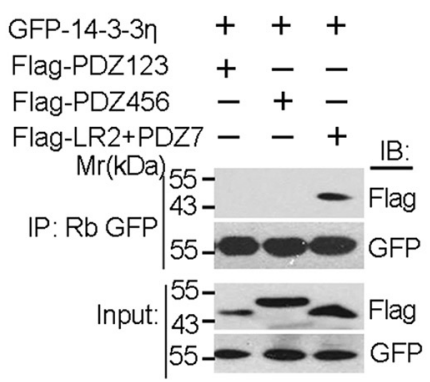

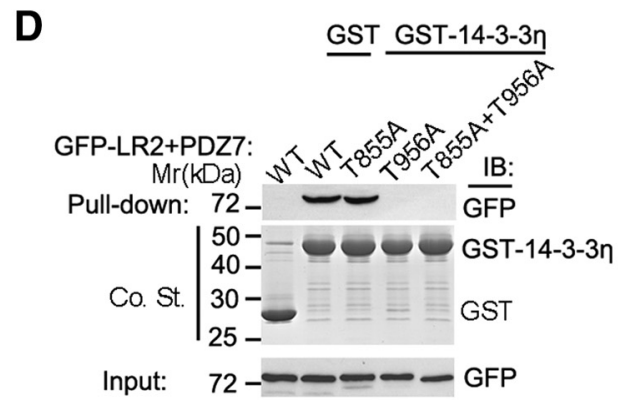

D

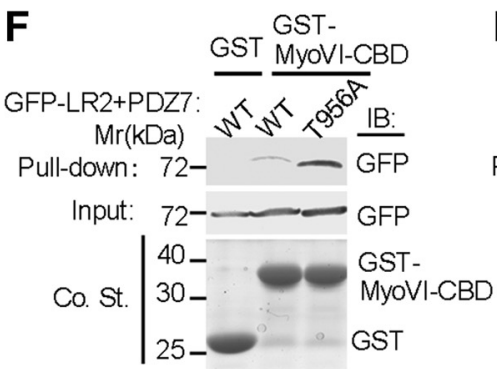

G

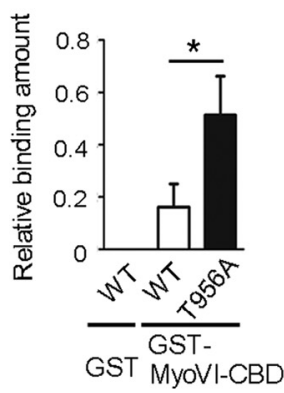

E
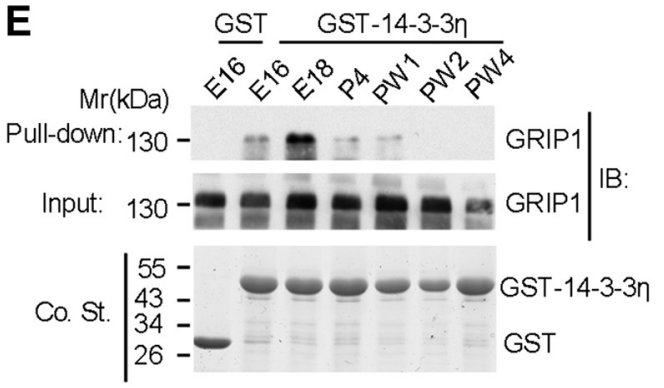

H Insulin
Wortman
Mr(kDa)
ull-down:
Input:
Co. St. GFP-LR2+PDZ7

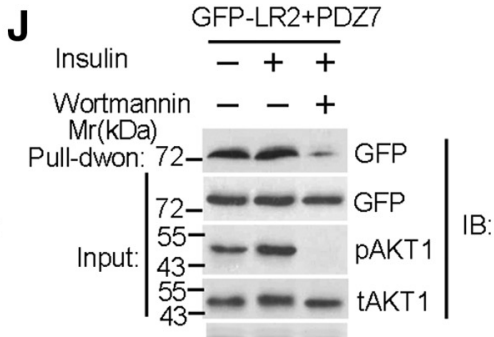

Co. St. 50- GST-14-3-3n

B.

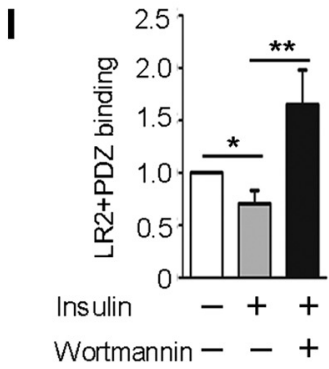

K

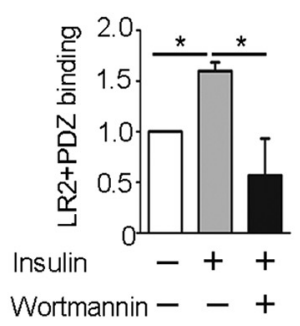

Figure 7. Phosphorylation of GRIP1 ${ }^{956 \mathrm{~T}}$ switches its binding partner from myosin VI to 14-3-3 protein. $A$, The GRIP1 fragment, including GRIP1 ${ }^{956 \mathrm{~T}}$ site (asterisk), was predicted to contain a 14-3-3 binding motif (arrow). $\boldsymbol{B}$, Pull-down of overexpressed Flag-GRIP1 by three GST-tagged brain-enriched 14-3-3 isoforms $(\gamma, \eta$, and $\zeta$ ) in HEK293T cell lysates. Co. St., Coomassie blue staining; IB, immunoblotting. C, Cell lysates from HEK293T cells overexpressing the indicated constructs were immunoprecipitated (IP) with anti-GFP antibody followed by IB. D, Pull-down of overexpressed WT or the indicated phosphodead mutants of GFP-LR2 + PDZ7 by GST-14-3-3 $\eta$ in HEK293T cell lysates. E, Pull-down of endogenous GRIP1 by GST-14-3-3 $\eta$ in mouse brain homogenates. E, Embryonic day; P, Postnatal day; PW, Postnatal week. F, Pull-down of overexpressed WT or T956A of GFP-LR2 + PDZ7 by GST-myosin VI-CBD in HEK293T cell lysates. G, Quantification of the relative binding of WT or T956A of GFP-LR2 + PDZ7 to GST-myosin VI-CBD in $\boldsymbol{F}(n=3)$. $\boldsymbol{H}, \boldsymbol{J}$, HEK293T cells overexpressing GFP-LR2 + PDZ7 were treated as indicated and used for a GST-myosin VI-CBD ( $\boldsymbol{H}$ ) or GST-14-3-3 $\eta(J)$ pull-down assay. The pull-down precipitates were analyzed by IB with the indicated antibodies. $\mathbf{I}, \boldsymbol{K}$, Quantification of the relative binding of GFP-LR2 + PDZ7 to GST-myosin VI-CBD $(\boldsymbol{I})$ in $\boldsymbol{H}$ or to GST-14-3-3 $\eta(\boldsymbol{K})$ in $\boldsymbol{J}(n=3)$. For $\boldsymbol{G}, \boldsymbol{I}$, and $\boldsymbol{K}$, data are mean \pm SEM. ${ }^{*} p<0.05,{ }^{* *} p<0.01$.

GRIP1 (GFP-LR2+PDZ7), which contains the binding region of myosin VI (Fig. 5C,D), was purified from HEK293T cells and subjected to mass spectrometry analysis. A phosphorylation site, GRIP1 ${ }^{956 \mathrm{~T}}$, was identified (Fig. $6 A$ ) and found to be conserved among many eukaryotes (Fig. 6B). We then generated a phosphorylation-specific (denoted pGRIP1) antibody against GRIP1 ${ }^{956 \mathrm{~T}}$. With this pGRIP1 antibody, we detected a specific band of GFPLR2 + PDZ7, which was almost eliminated after treatment with either lambda phosphatase or calf alkaline phosphatase (Fig. 6C).
Furthermore, we generated the mimetic phosphodead mutants T855A, T956A, and T855A + T956A of GFP-LR2 + PDZ7. A specific band was detected by the pGRIP1 antibody in the wild type (WT) and T855A, but not in T956A and T855A+T956A of the GFPLR2+PDZ7-overexpressing HEK293T cell lysates (Fig. 6D). Finally, we probed mouse brain (Fig. 6E) and hippocampal homogenates (Fig. $6 F$ ) with pGRIP1 antibody. GRIP1 ${ }^{956 \mathrm{~T}}$ phosphorylation was detected at E14, and gradually increased with development. However, it sharply decreased during postnatal stages (Fig. 
A



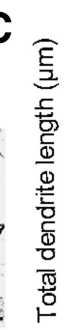

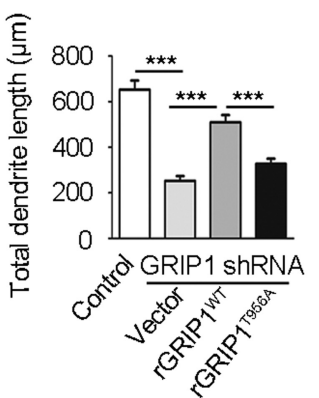

D

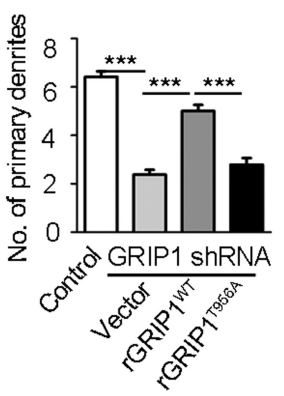

E

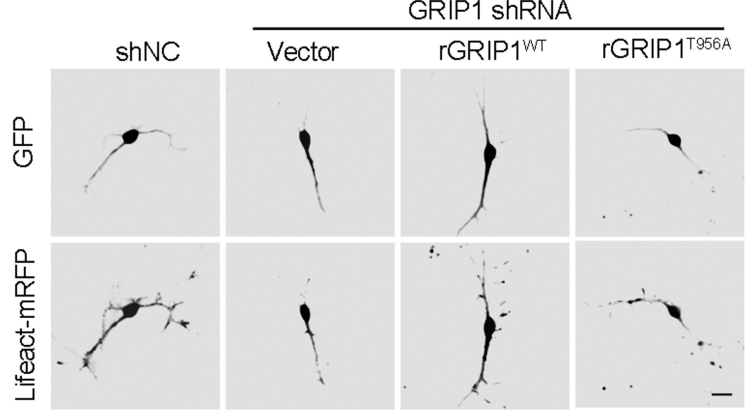

$\mathbf{F}$

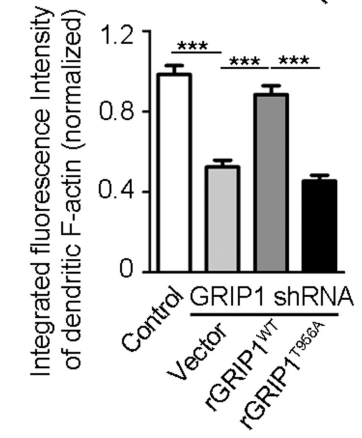

Figure 8. Phosphorylation of GRIP1 ${ }^{956 \mathrm{~T}}$ is required for F-actin organization and dendritic morphology. A, Immunoblotting (IB) of Flag-GRIP1 from lysates of HEK293T cells transfected with the indicated plasmids. $r$, Rat. $B$, Representative images of cultured hippocampal GRIP1 shRNA transfected neurons rescued by rGRIP1 ${ }^{\text {WT }}$ or rGRIP1 ${ }^{\text {T956A }}$ at 7 DIV for $72 \mathrm{~h}$. The GFP signal from the shRNA vector was used to visualize neuronal morphology. Scale bar, $50 \mu \mathrm{m}$. $\boldsymbol{C}$, Quantification of the total dendritic length of neurons in $\boldsymbol{B}(n \geq 30$ cells). $\boldsymbol{D}$, Quantification of the number of primary dendrites of neurons in $\boldsymbol{B}$ ( $n \geq 30$ cells). $\boldsymbol{E}$, Representative images of the cultured hippocampal neurons transfected with Lifeact-GFP together with shNC, with GRIP1 shRNA, with GRIP1 shRNA + rGRIP1 ${ }^{\text {WT }}$, or with GRIP1 shRNA + rGRIP1 ${ }^{\text {T956A }}$ at 5 DIV for $48 \mathrm{~h}$. Scale bar, $10 \mu \mathrm{m}$. $\boldsymbol{F}$, Quantification of the integrated fluorescence intensity of dendritic F-actin in $\boldsymbol{E}(n \geq 30$ cells). For $\boldsymbol{C}, \boldsymbol{D}$, and $\boldsymbol{F}$, data are mean \pm SEM. ${ }^{* * *} p<0.001$.

$6 E, F)$, indicating that phosphorylation of GRIP1 ${ }^{956 \mathrm{~T}}$ is regulated during development in vivo.

A bioinformatics analysis (Obenauer et al., 2003) predicted that AKT1 phosphorylates GRIP1 ${ }^{956 \mathrm{~T}}$ (Fig. 6B). We first testified the interaction of GRIP1-LR2+PDZ7 with AKT1 using pulldown assay (Fig. 6G). Then, depletion of endogenous AKT1 (Vasudevan et al., 2009) in HEK293T cells overexpressing GFPLR2+PDZ7 decreased the phospho-GRIP1 ${ }^{956 \mathrm{~T}}$ levels (Fig. $6 H$ ). Moreover, after serum deprivation for $36 \mathrm{~h}$, AKT1 activation was inhibited, and phospho-GRIP1 ${ }^{956 \mathrm{~T}}$ was suppressed in HEK293T cells overexpressing GFP-LR2 + PDZ7 (Fig. 6I). The AKT1 activator insulin $(5 \mu \mathrm{g} / \mathrm{ml})$ efficiently restored the level of phosphoGRIP1 ${ }^{956 \mathrm{~T}}$, which was then remarkably compromised in the presence of AKT1 inactivator wortmannin (100 nM; Fig. 6I). However, these two drugs failed to affect the phosphodead mutant T956A of GFP-LR2 + PDZ7 (Fig. 6J). Finally, we applied the drug treatments to cultured hippocampal neurons and obtained similar results (Fig. $6 \mathrm{~K}$ ). These data suggest that AKT1 phosphorylates GRIP1 ${ }^{956 \mathrm{~T}}$.

\section{Phosphorylation of GRIP1 ${ }^{956 \mathrm{~T}}$ switches its binding partner from myosin VI to 14-3-3 protein}

14-3-3 proteins, abundant in brain, bind to phosphorylated targets, and modulate their structures and functions (Aitken, 2006). GRIP1 ${ }^{956 \mathrm{~T}}$ was predicted to contain the binding motif of 14-3-3: 953-R-S-N-T-L-P-958 (Fig. 7A). Thus, we investigated whether the three major brain-enriched 14-3-3 isoforms $(\gamma, \eta$, and $\zeta)$ interacted with GRIP1. Using Flag-GRIP1 overexpressing HEK293T cell lysates, we found that GRIP1 was pulled down by all three GST-fused 14-3-3 isoforms (Fig. 7B). As 14-3-3 $\eta$ showed the strongest interaction with GRIP1, we focused on this isoform in further experiments. We then confirmed that the GRIP1-LR2+PDZ7 fragment containing the 956T site also bound to 14-3-3 (Fig. 7C). Furthermore, the mutants T956A and T855A+T956A, but not T855A of GFP-LR2 + PDZ7, completely abolished the 14-3-3 binding (Fig. 7D). More importantly, pulldown assay showed that GST-14-3-3 interacted with endogenous GRIP1, mainly in E16 and E18 brain homogenates (Fig. 7E), when GRIP1 was highly phosphorylated in vivo (Fig. $6 E$ ). Collectively, these data suggest that the phosphorylation of GRIP1 ${ }^{956 \mathrm{~T}}$ is crucial for 14-3-3 binding.

As the GRIP-LR2 + PDZ7 fragment interacted with both myosin VI and 14-3-3, we assumed that the phosphorylation of GRIP1 ${ }^{\text {956T }}$ might serve as a switch in shifting its interaction partner from myosin VI to 14-3-3. To test this, we used GST-myosin VI-CBD to pull down HEK293T cell lysates that overexpressed WT or T956A of GFP-LR2+PDZ7. We found that myosin VI-CBD bound to 2.8fold more T956A than WT of GFP-LR2+PDZ7 (Fig. 7F, G; $p<$ 0.05 ). Additionally, insulin treatment activated AKT1 and increased the level of phospho-GRIP1 ${ }^{956 \mathrm{~T}}$, which resulted in 1.58 -fold more $14-3-3$ but 0.68 -fold less myosin VI binding (Figs. $7 H-K ; p<0.05$ ). In contrast, the combination of insulin and wortmannin treatment significantly decreased the level of phospho-GRIP $1^{956 \mathrm{~T}}$, which resulted in 0.57 -fold less 14-3-3 but 1.7-fold more myosin VI binding compared with control (Fig. $7 H-K ; I, p<0.01 ; K, p<0.05$ ). Thus, whether GRIP1 ${ }^{956 \mathrm{~T}}$ is phosphorylated can serve as a switch in regulating its binding partner.

\section{GRIP1 ${ }^{956 \mathrm{~T}}$ phosphorylation regulates dendritic morphology and F-actin organization}

To assess the role of GRIP1 ${ }^{956 \mathrm{~T}}$ phosphorylation on dendritic morphogenesis, we overexpressed rat GRIP1 ${ }^{\mathrm{WT}}$ ( $\mathrm{rGRIP} 1^{\mathrm{WT}}$ ) or GRIP1 ${ }^{\text {T956A }}$ (rGRIP1 ${ }^{\text {T956A }}$ ) to restore the expression of GRIP1 in GRIP1 shRNA-transfected hippocampal neurons (Fig. $8 A, B$ ). As expected, rGRIP1 ${ }^{\mathrm{WT}}$ restored the GRIP1 shRNA-induced defects in the total dendritic length and the number of primary dendrites. 
Intriguingly, overexpression of rGRIP1 ${ }^{\mathrm{T} 956 \mathrm{~A}} \mathrm{did}$ not restore the GRIP1-depletion phenotype as effectively as GRIP1 ${ }^{\text {WT }}$ (Fig. $8 B-D ; p<0.001)$.

Finally, we examined the effects of GRIP1 ${ }^{956 \mathrm{~T}}$ on F-actin organization by Lifeact-GFP. GRIP1 knockdown in cultured hippocampal neurons resulted in a decrease in F-actin intensity by $46.2 \%$, similar to Trip6 knockdown (Fig. 5P, Q; $p<0.001$; Fig. $8 E, F ; p<0.001)$. Then, we overexpressed $\mathrm{rGRIP}^{\mathrm{WT}}$ or rGRIP1 ${ }^{\text {T956A }}$ in GRIP1 shRNA-transfected hippocampal neurons, and found only rGRIP $1{ }^{\mathrm{WT}}$ could restore F-actin intensity (Fig. $8 E, F ; p<0.001$ ), indicating that GRIP1 ${ }^{956 \mathrm{~T}}$ is crucial for F-actin organization and dendritic growth.

\section{Discussion}

In this study, we provide evidence that Trip6, together with GRIP1 and myosin VI, regulates F-actin organization and dendritic morphogenesis. Furthermore, in the mouse hippocampus, GRIP1 ${ }^{956 \mathrm{~T}}$ is highly phosphorylated during embryonic development. The phosphorylation of GRIP1 ${ }^{956 \mathrm{~T}}$ by AKT1 facilitates its interaction with 14-3-3 protein, which sequesters GRIP1 from myosin VI, and results in the dissociation of the myosin VI from GRIP1. Therefore, we propose that phosphorylation of GRIP1 ${ }^{956 \mathrm{~T}}$ acts as a switch to determine its binding partner, and regulates dendritic morphogenesis.

Trip6 is essential for actin assembly and reorganization in non-neuronal cells (Sanz-Rodriguez et al., 2004; Bai et al., 2007). The present results demonstrate that Trip6 is highly expressed during hippocampal development, regulates F-actin organization, and is required for dendritic morphogenesis. In the embryonic stage $\sim \mathrm{E} 15$, when neurogenesis and differentiation peak in the hippocampus, actin is considered to be highly dynamic, and this greatly contributes to proper dendritic growth and branch formation (Morgane et al., 1993; Finlay and Darlington, 1995; Donovan and Dyer, 2005). Our results consistently show that, during the midstage of embryonic development of the mouse hippocampus, GRIP1 ${ }^{956 \mathrm{~T}}$ phosphorylation level is relatively high. This phosphorylation may regulate precise localization of Trip6 in dendrites, which in turn increases actin dynamics and controls dendritic development. Furthermore, overexpression of GRIP1 ${ }^{\mathrm{T} 956 \mathrm{~A}}$ fails to restore the defects in the total dendritic length and the number of primary dendrites. Probably, GRIP1 ${ }^{\text {T956A }}$ reduces the actin dynamics due to incorrect localization of Trip6, and inhibits dendritic growth. Therefore, elucidating the mechanism of spatiotemporal delivery of Trip6 to the destination of dendrites will improve our understanding of the control of dendritic development.

Our results show that myosin VI is essential for dendritic morphogenesis. Compared with knockdown of Trip6 or GRIP1, the disruption of endogenous myosin VI with either an shRNA or a dominant negative mutant exaggerated the defects in dendritic morphology, with no or only one dendrite left in some neurons. Thus, myosin VI may function in multiple ways. One possibility may be disruption of the Golgi apparatus (Warner et al., 2003). Previously, myosin VI was reported to regulate the maintenance of Golgi morphology (Sahlender et al., 2005). The defective transportation that follows disruption of the Golgi apparatus could contribute to the defects in dendritic development (Horton et al., 2005). The other possibility is that multiple cargoes transported by myosin VI might also be involved in dendritic development. This is plausible as some receptors, such as the epidermal growth factor receptor (Chibalina et al., 2010) and AMPA receptors (Osterweil et al., 2005), have been reported to be transported by myosin VI. In addition, adaptor proteins and scaffolding pro- teins, such as GRIP1, Dab2 (Morris et al., 2002), and SAP97 (Osterweil et al., 2005), mediate the interaction of myosin VI with cargoes, and thus increase their diversity.

The regulation of actin filaments plays a significant role in neuronal morphogenesis (Luo, 2002; Zito et al., 2004). Consistently, in this study, our data suggest the function of Trip6 in regulating F-actin organization and ultimately controlling both the total dendritic length and the number of primary dendrites. Also, overexpression of Trip6 can fully rescue the defects of dendritic morphogenesis in GRIP1 knockdown neurons. Considering the function of Trip6 at cell-cell and cell-matrix adhesions in non-neuronal cells (Takizawa et al., 2006; Bai et al., 2007), we cannot rule out the possibility that Trip6 also regulates dendritic morphogenesis by affecting synaptic adhesion and the resultant signal transmission.

The protein 14-3-3 mainly binds to phosphorylated targets and plays important roles in a wide range of vital regulatory processes, such as protein trafficking and signal transduction (Darling et al., 2005; van Heusden, 2005; Morrison, 2009). The protein 14-3-3 functions in neuronal processes by interacting with and regulating the trafficking of phosphorylated targets (Rong et al., 2007; Yang et al., 2008). Here, we find that 14-3-3 binds to AKT1-mediated phospho-GRIP1 ${ }^{956 \mathrm{~T}}$ in neurons, which leads to myosin VI disassociation and serves as a control point for regulating dendritic morphogenesis. Consistently, as we prepared our manuscript, another research group showed that GRIP1/14-3-3 pathway plays a crucial function in kinesin-1mediated cargo trafficking during dendrite development and that GRIP $1^{956 \mathrm{~T}}$ is crucial for dendritic development (Geiger et al., 2014). It remains unknown, however, under physiological conditions, which stimuli or signals activate AKT1 to phosphorylate GRIP $1{ }^{956 \mathrm{~T}}$ and cause 14-3-3 binding to the targets. In addition, it is worthy of note that a previous study failed to detect any phosphorylation signal in a GRIP1 ${ }^{956 \mathrm{~T}}$-containing fragment (amino acids 933-982; Kulangara et al., 2007); this is a very short fragment fused with a large GST tag, which might lead to masking of the phosphorylation of GRIP1 ${ }^{956 \mathrm{~T}}$.

Previous reports indicated that the GRIP1-LR2 region directly binds to the CBD of kinesin-1, and that is essential for dendritic morphogenesis (Setou et al., 2002; Hoogenraad et al., 2005). Intriguingly, our data show that GRIP1-LR2 also interacts with the CBD of myosin VI, and GRIP1 ${ }^{956 \mathrm{~T}}$ in this region is crucial for regulating their interaction. It is widely accepted that the cooperation of microtubules and F-actin filaments directly regulates cell polarization, morphogenesis, and movement (Tirnauer, 2002; Schaefer et al., 2008). GRIP1 as an adaptor protein may associate with both kinesin-1 and myosin VI, and thus mediate rapid and effective intracellular delivery along both microtubule and actin tracks. Further investigation of the role of GRIP1 in the cooperation of microtubule-based and F-actin-based motor proteins is promising.

\section{References}

Aitken A (2006) 14-3-3 proteins: a historic overview. Semin Cancer Biol 16:162-172. CrossRef Medline

Bai CY, Ohsugi M, Abe Y, Yamamoto T (2007) ZRP-1 controls Rho GTPase-mediated actin reorganization by localizing at cell-matrix and cell-cell adhesions. J Cell Sci 120:2828-2837. CrossRef Medline

Chibalina MV, Poliakov A, Kendrick-Jones J, Buss F (2010) Myosin VI and optineurin are required for polarized EGFR delivery and directed migration. Traffic 11:1290-1303. CrossRef Medline

Cuppen E, van Ham M, Wansink DG, de Leeuw A, Wieringa B, Hendriks W (2000) The zyxin-related protein TRIP6 interacts with PDZ motifs in the adaptor protein RIL and the protein tyrosine phosphatase PTP-BL. Eur J Cell Biol 79:283-293. CrossRef Medline 
Darling DL, Yingling J, Wynshaw-Boris A (2005) Role of 14-3-3 proteins in eukaryotic signaling and development. Curr Top Dev Biol 68:281-315. CrossRef Medline

Da Silva JS, Medina M, Zuliani C, Di Nardo A, Witke W, Dotti CG (2003) RhoA/ROCK regulation of neuritogenesis via profilin IIa-mediated control of actin stability. J Cell Biol 162:1267-1279. CrossRef Medline

Davidkova G, Carroll RC (2007) Characterization of the role of microtubule-associated protein $1 \mathrm{~B}$ in metabotropic glutamate receptormediated endocytosis of AMPA receptors in hippocampus. J Neurosci 27:13273-13278. CrossRef Medline

Dong H, O’Brien RJ, Fung ET, Lanahan AA, Worley PF, Huganir RL (1997) GRIP: a synaptic PDZ domain-containing protein that interacts with AMPA receptors. Nature 386:279-284. CrossRef Medline

Dong H, Zhang P, Liao D, Huganir RL (1999a) Characterization, expression, and distribution of GRIP protein. Ann N Y Acad Sci 868:535-540. CrossRef Medline

Dong H, Zhang P, Song I, Petralia RS, Liao D, Huganir RL (1999b) Characterization of the glutamate receptor-interacting proteins GRIP1 and GRIP2. J Neurosci 19:6930-6941. Medline

Donovan SL, Dyer MA (2005) Regulation of proliferation during central nervous system development. Semin Cell Dev Biol 16:407-421. CrossRef Medline

Finlay BL, Darlington RB (1995) Linked regularities in the development and evolution of mammalian brains. Science 268:1578-1584. CrossRef Medline

Frank DJ, Noguchi T, Miller KG (2004) Myosin VI: a structural role in actin organization important for protein and organelle localization and trafficking. Curr Opin Cell Biol 16:189-194. CrossRef Medline

Geiger JC, Lipka J, Segura I, Hoyer S, Schlager MA, Wulf PS, Weinges S, Demmers J, Hoogenraad CC, Acker-Palmer A (2014) The GRIP1/143-3 pathway coordinates cargo trafficking and dendrite development. Dev Cell 28:381-393. CrossRef Medline

Hoogenraad CC, Milstein AD, Ethell IM, Henkemeyer M, Sheng M (2005) GRIP1 controls dendrite morphogenesis by regulating EphB receptor trafficking. Nat Neurosci 8:906-915. CrossRef Medline

Horton AC, Rácz B, Monson EE, Lin AL, Weinberg RJ, Ehlers MD (2005) Polarized secretory trafficking directs cargo for asymmetric dendrite growth and morphogenesis. Neuron 48:757-771. CrossRef Medline

Jiang M, Chen G (2006) High Ca2+-phosphate transfection efficiency in low-density neuronal cultures. Nat Protoc 1:695-700. CrossRef Medline

Jung EJ, Liu G, Zhou W, Chen X (2006) Myosin VI is a mediator of the p53-dependent cell survival pathway. Mol Cell Biol 26:2175-2186. CrossRef Medline

Kulangara K, Kropf M, Glauser L, Magnin S, Alberi S, Yersin A, Hirling H (2007) Phosphorylation of glutamate receptor interacting protein 1 regulates surface expression of glutamate receptors. J Biol Chem 282:23952404. CrossRef Medline

Landis SC, Amara SG, Asadullah K, Austin CP, Blumenstein R, Bradley EW, Crystal RG, Darnell RB, Ferrante RJ, Fillit H, Finkelstein R, Fisher M, Gendelman HE, Golub RM, Goudreau JL, Gross RA, Gubitz AK, Hesterlee SE, Howells DW, Huguenard J, et al. (2012) A call for transparent reporting to optimize the predictive value of preclinical research. Nature 490:187-191. CrossRef Medline

Lee CW, Vitriol EA, Shim S, Wise AL, Velayutham RP, Zheng JQ (2013) Dynamic localization of G-actin during membrane protrusion in neuronal motility. Curr Biol 23:1046-1056. CrossRef Medline

Lin VT, Lin FT (2011) TRIP6: an adaptor protein that regulates cell motility, antiapoptotic signaling and transcriptional activity. Cell Signal 23:16911697. CrossRef Medline

Luo L (2002) Actin cytoskeleton regulation in neuronal morphogenesis and structural plasticity. Annu Rev Cell Dev Biol 18:601-635. CrossRef Medline

Ma L, Greenwood JA, Schachner M (2011) CRP1, a protein localized in filopodia of growth cones, is involved in dendritic growth. J Neurosci 31:16781-16791. CrossRef Medline

Mao L, Takamiya K, Thomas G, Lin DT, Huganir RL (2010) GRIP1 and 2 regulate activity-dependent AMPA receptor recycling via exocyst complex interactions. Proc Natl Acad Sci U S A 107:19038-19043. CrossRef Medline

Matsubara D, Horiuchi SY, Shimono K, Usui T, Uemura T (2011) The seven-pass transmembrane cadherin Flamingo controls dendritic self- avoidance via its binding to a LIM domain protein, Espinas, in Drosophila sensory neurons. Genes Dev 25:1982-1996. CrossRef Medline

Mattson MP (1999) Establishment and plasticity of neuronal polarity. J Neurosci Res 57:577-589. Medline

Morgane PJ, Austin-LaFrance R, Bronzino J, Tonkiss J, Díaz-Cintra S, Cintra L, Kemper T, Galler JR (1993) Prenatal malnutrition and development of the brain. Neurosci Biobehav Rev 17:91-128. CrossRef Medline

Morris SM, Arden SD, Roberts RC, Kendrick-Jones J, Cooper JA, Luzio JP, Buss F (2002) Myosin VI binds to and localises with Dab2, potentially linking receptor-mediated endocytosis and the actin cytoskeleton. Traffic 3:331-341. CrossRef Medline

Morrison DK (2009) The 14-3-3 proteins: integrators of diverse signaling cues that impact cell fate and cancer development. Trends Cell Biol 19: 16-23. CrossRef Medline

Obenauer JC, Cantley LC, Yaffe MB (2003) Scansite 2.0: proteome-wide prediction of cell signaling interactions using short sequence motifs. Nucleic Acids Res 31:3635-3641. CrossRef Medline

Osterweil E, Wells DG, Mooseker MS (2005) A role for myosin VI in postsynaptic structure and glutamate receptor endocytosis. J Cell Biol 168: 329-338. CrossRef Medline

Pontrello CG, Sun MY, Lin A, Fiacco TA, DeFea KA, Ethell IM (2012) Cofilin under control of beta-arrestin-2 in NMDA-dependent dendritic spine plasticity, long-term depression (LTD), and learning. Proc Natl Acad Sci U S A 109:E442-E451. CrossRef Medline

Riedl J, Crevenna AH, Kessenbrock K, Yu JH, Neukirchen D, Bista M, Bradke F, Jenne D, Holak TA, Werb Z, Sixt M, Wedlich-Soldner R (2008) Lifeact: a versatile marker to visualize F-actin. Nat Methods 5:605-607. CrossRef Medline

Roberts R, Lister I, Schmitz S, Walker M, Veigel C, Trinick J, Buss F, Kendrick-Jones J (2004) Myosin VI: cellular functions and motor properties. Philos Trans R Soc Lond B Biol Sci 359:1931-1944. CrossRef Medline

Rong J, Li S, Sheng G, Wu M, Coblitz B, Li M, Fu H, Li XJ (2007) 14-3-3 protein interacts with Huntingtin-associated protein 1 and regulates its trafficking. J Biol Chem 282:4748-4756. CrossRef Medline

Sahlender DA, Roberts RC, Arden SD, Spudich G, Taylor MJ, Luzio JP, Kendrick-Jones J, Buss F (2005) Optineurin links myosin VI to the Golgi complex and is involved in Golgi organization and exocytosis. J Cell Biol 169:285-295. CrossRef Medline

Sanz-Rodriguez F, Guerrero-Esteo M, Botella LM, Banville D, Vary CP, Bernabéu C (2004) Endoglin regulates cytoskeletal organization through binding to ZRP-1, a member of the Lim family of proteins. J Biol Chem 279:32858-32868. CrossRef Medline

Schaefer AW, Schoonderwoert VT, Ji L, Mederios N, Danuser G, Forscher P (2008) Coordination of actin filament and microtubule dynamics during neurite outgrowth. Dev Cell 15:146-162. CrossRef Medline

Setou M, Seog DH, Tanaka Y, Kanai Y, Takei Y, Kawagishi M, Hirokawa N (2002) Glutamate-receptor-interacting protein GRIP1 directly steers kinesin to dendrites. Nature 417:83-87. CrossRef Medline

Smyth JW, Vogan JM, Buch PJ, Zhang SS, Fong TS, Hong TT, Shaw RM (2012) Actin cytoskeleton rest stops regulate anterograde traffic of connexin 43 vesicles to the plasma membrane. Circ Res 110:978-989. CrossRef Medline

Steiner P, Alberi S, Kulangara K, Yersin A, Sarria JC, Regulier E, Kasas S, Dietler G, Muller D, Catsicas S, Hirling H (2005) Interactions between NEEP21, GRIP1 and GluR2 regulate sorting and recycling of the glutamate receptor subunit GluR2. EMBO J 24:2873-2884. CrossRef Medline

Suh YH, Terashima A, Petralia RS, Wenthold RJ, Isaac JT, Roche KW, Roche PA (2010) A neuronal role for SNAP-23 in postsynaptic glutamate receptor trafficking. Nat Neurosci 13:338-343. CrossRef Medline

Sweeney HL, Houdusse A (2007) What can myosin VI do in cells? Curr Opin Cell Biol 19:57-66. CrossRef Medline

Takizawa N, Smith TC, Nebl T, Crowley JL, Palmieri SJ, Lifshitz LM, Ehrhardt AG, Hoffman LM, Beckerle MC, Luna EJ (2006) Supervillin modulation of focal adhesions involving TRIP6/ZRP-1. J Cell Biol 174:447-458. CrossRef Medline

Teng J, Takei Y, Harada A, Nakata T, Chen J, Hirokawa N (2001) Synergistic effects of MAP2 and MAP1B knockout in neuronal migration, dendritic outgrowth, and microtubule organization. J Cell Biol 155:65-76. CrossRef Medline

Tirnauer JS (2002) Coupled zones of F-actin and microtubule movement in polarized cells. Dev Cell 3:152-153. CrossRef Medline 
van Heusden GP (2005) 14-3-3 proteins: regulators of numerous eukaryotic proteins. IUBMB Life 57:623-629. Medline

Vasudevan KM, Barbie DA, Davies MA, Rabinovsky R, McNear CJ, Kim JJ, Hennessy BT, Tseng H, Pochanard P, Kim SY, Dunn IF, Schinzel AC, Sandy P, Hoersch S, Sheng Q, Gupta PB, Boehm JS, Reiling JH, Silver S, Lu $\mathrm{Y}$, et al. (2009) AKT-independent signaling downstream of oncogenic PIK3CA mutations in human cancer. Cancer Cell 16:21-32. CrossRef Medline

Warner CL, Stewart A, Luzio JP, Steel KP, Libby RT, Kendrick-Jones J, Buss F (2003) Loss of myosin VI reduces secretion and the size of the Golgi in fibroblasts from Snell's waltzer mice. EMBO J 22:569-579. Medline

Wyszynski M, Valtschanoff JG, Naisbitt S, Dunah AW, Kim E, Standaert DG, Weinberg R, Sheng M (1999) Association of AMPA receptors with a subset of glutamate receptor-interacting protein in vivo. J Neurosci 19: 6528-6537. Medline

Wyszynski M, Kim E, Dunah AW, Passafaro M, Valtschanoff JG, Serra-Pagès C, Streuli M, Weinberg RJ, Sheng M (2002) Interaction between GRIP and liprin-alpha/SYD2 is required for AMPA receptor targeting. Neuron 34:39-52. Medline

Yang X, Luo C, Cai J, Pierce WM, Tezel G (2008) Phosphorylationdependent interaction with 14-3-3 in the regulation of bad trafficking in retinal ganglion cells. Invest Ophthalmol Vis Sci 49:2483-2494. CrossRef Medline

Zito K, Knott G, Shepherd GM, Shenolikar S, Svoboda K (2004) Induction of spine growth and synapse formation by regulation of the spine actin cytoskeleton. Neuron 44:321-334. CrossRef Medline 